\author{
WALDEN \\ UNIVERSITY \\ A higher degree. A higher purpose.
}

Walden University ScholarWorks

Walden Dissertations and Doctoral Studies

2015

\title{
The Association Between Exhaled Nitric Oxide in Exhaled Breath Condensate and Chronic Obstructive Pulmonary Disease
}

Colin Mitchell

Walden University

Follow this and additional works at: https://scholarworks.waldenu.edu/dissertations

Part of the Epidemiology Commons, and the Public Health Education and Promotion Commons

This Dissertation is brought to you for free and open access by the Walden Dissertations and Doctoral Studies Collection at ScholarWorks. It has been accepted for inclusion in Walden Dissertations and Doctoral Studies by an authorized administrator of ScholarWorks. For more information, please contact ScholarWorks@waldenu.edu. 


\title{
Walden University
}

\author{
College of Health Sciences
}

This is to certify that the doctoral dissertation by

\author{
Colin Mitchell
}

has been found to be complete and satisfactory in all respects, and that any and all revisions required by the review committee have been made.

\author{
Review Committee \\ Dr. Ahmed Arif, Committee Chairperson, Public Health Faculty \\ Dr. Xianbin Li, Committee Member, Public Health Faculty \\ Dr. Kimberly Brownley, University Reviewer, Public Health Faculty
}

\section{Chief Academic Officer}

Eric Riedel, Ph.D.

Walden University

2015 


\begin{abstract}
The Association Between Exhaled Nitric Oxide in Exhaled Breath Condensate and Chronic Obstructive Pulmonary Disease

by

Colin Mitchell
\end{abstract}

MBA Marketing, Pace University 2003

BA Biology, University of Delaware, 1992

\author{
Dissertation Submitted in Partial Fulfillment \\ of the Requirements for the Degree of \\ Doctor of Philosophy \\ Public Health
}

Walden University

May 2015 


\begin{abstract}
Chronic obstructive pulmonary disease (COPD), a progressive and nonreversible disease, is a leading cause of mortality and morbidity throughout the world. Detecting COPD early in the disease process will help in decreasing later stage COPD severity. Because airway inflammation is a hallmark of COPD, it has been proposed that measuring exhaled nitric oxide, a marker of inflammation, in exhaled breath condensate could prove to be an inexpensive and efficient method to detect COPD in outpatient settings. Using the hypothetico-deductive theory as a guideline, this study used secondary data from the National Health and Nutrition Examination Survey 2007 to 2010 to test the association between exhaled nitric oxide (eNO), COPD, and COPD severity. In addition, this study explored whether occupation modifies the association between eNO and COPD. Descriptive statistics, chi-square analyses, and regression analyses were used to analyze data from a sample size of 10,214 individuals. The prevalence of COPD was $7.2 \%$, based on self-reported physician diagnoses and $11.4 \%$ based on prebronchodilator spirometry analysis, strengthening the argument that COPD is often under- or misdiagnosed in clinical settings. This study found no statistically significant association between eNO, COPD, and COPD severity, and occupational status did not appear to modify the association between eNO and COPD. The findings of this study highlight the importance of using objective measures such as spirometry in clinical settings for early diagnosis and management of COPD. Early diagnosis helps to slow the progression of the disease, resulting in fewer related comorbidities and complications.
\end{abstract}


The Association Between Exhaled Nitric Oxide in Exhaled Breath Condensate and Chronic Obstructive Pulmonary Disease by

Colin Mitchell

MBA Marketing, Pace University 2003

BA Biology, University of Delaware, 1992

\author{
Dissertation Submitted in Partial Fulfillment \\ of the Requirements for the Degree of \\ Doctor of Philosophy \\ Public Health
}

Walden University

May 2015 


\section{Acknowledgments}

I would like to take this opportunity to express my gratitude to everyone who provided guidance and support during the dissertation process. First and foremost, I would like to thank my Chair, Dr. Arif Ahmed, for his guidance, insight, and patience. I would like to thank Dr. Xiabin Li and Ms. Alisa Stephens for their statistical support during the dissertation process. To my editor, Mrs. Carrie Crompton, thank you for your guidance. I would like to thank my family, especially my girls Zoe, Kiera, and Alexa for being there throughout the entire process. Last but not least, I could not have done this without the support from my partner, Jennifer Lathrop. 
Table of Contents

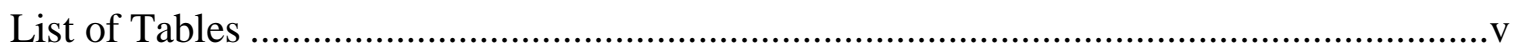

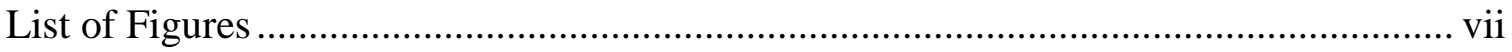

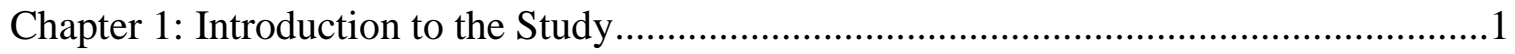

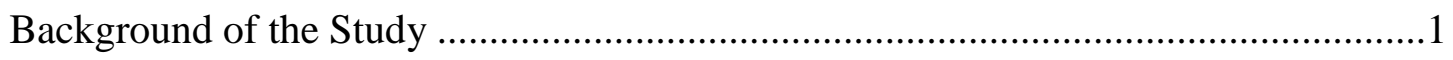

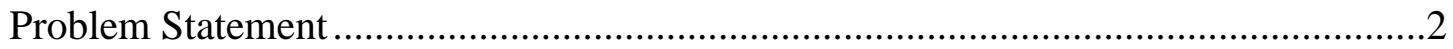

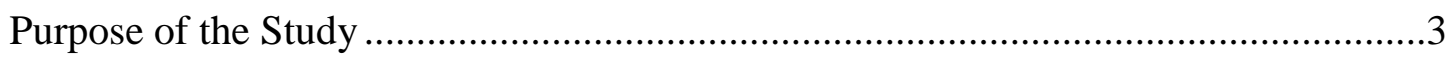

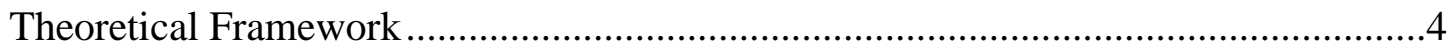

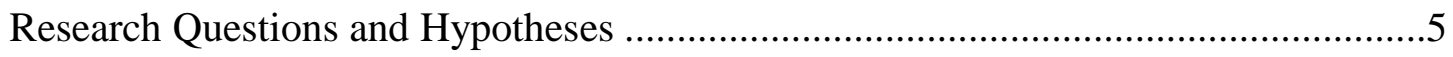

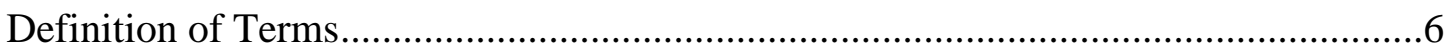

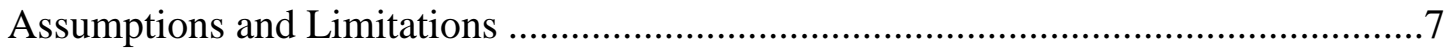

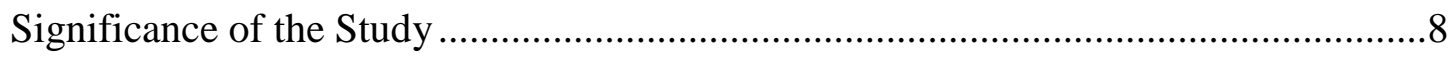

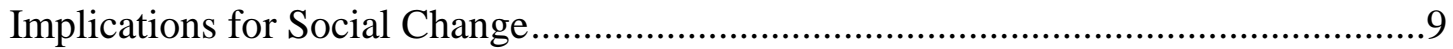

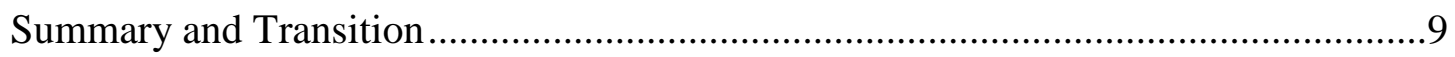

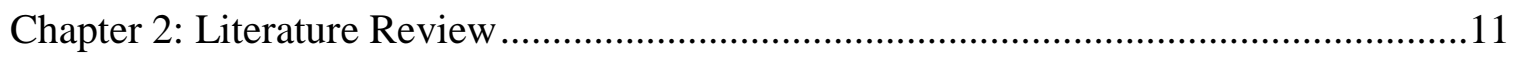

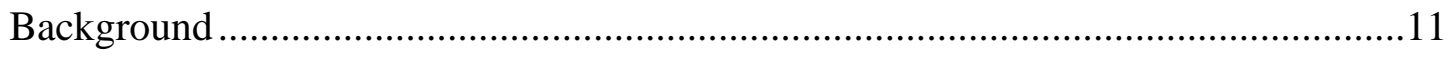

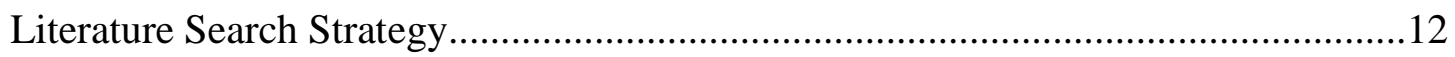

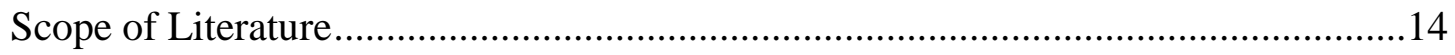

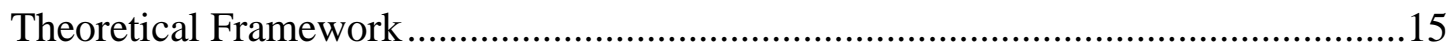

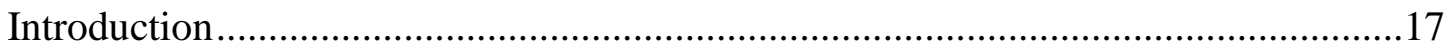

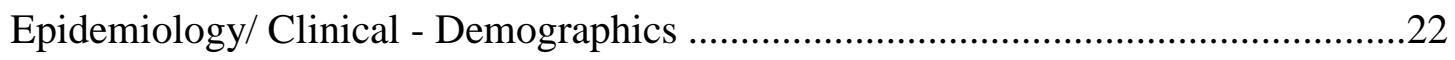

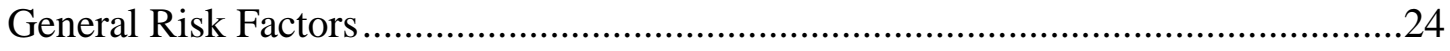




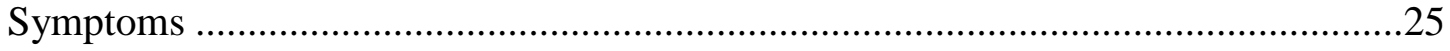

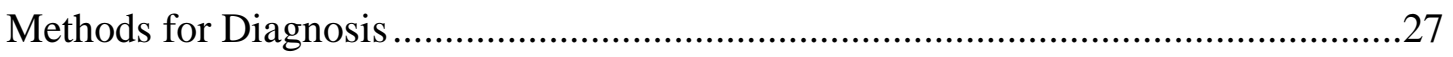

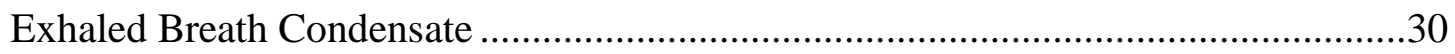

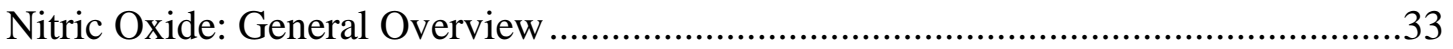

Nitric Oxide: Association Between COPD and Nitric Oxide …………………...........36

Nitric Oxide: COPD and Severity..........................................................................38

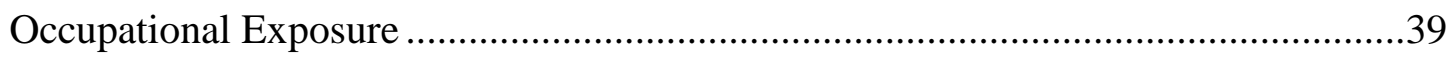

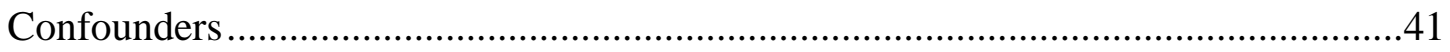

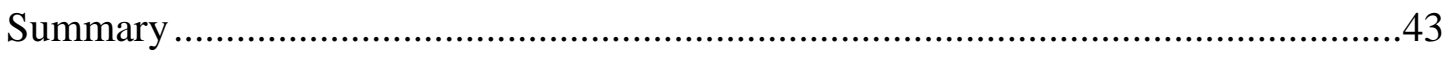

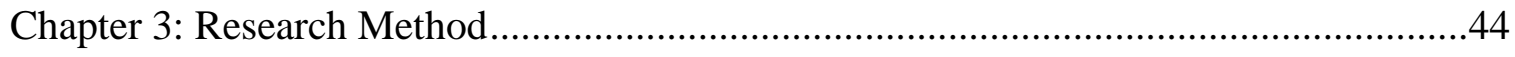

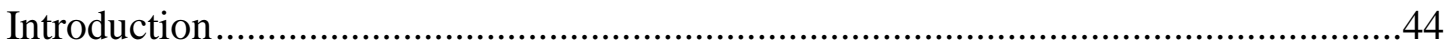

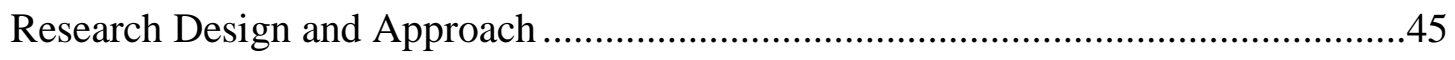

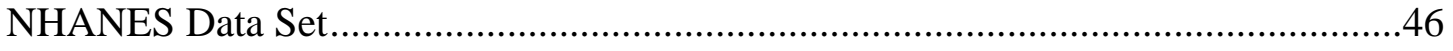

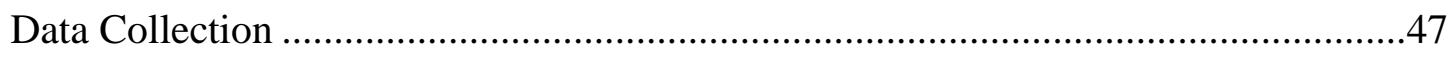

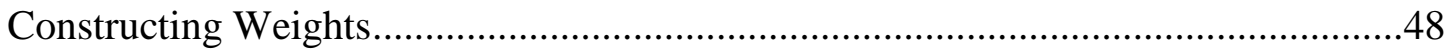

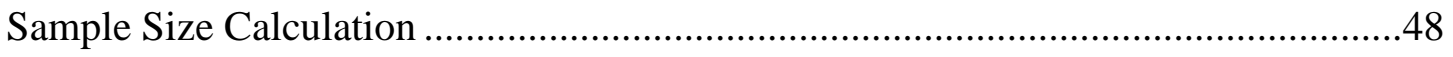

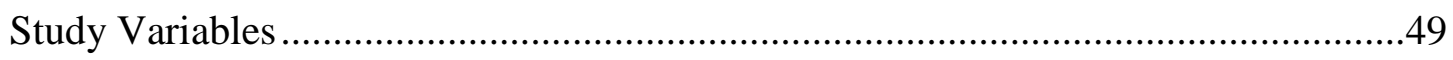

Dependent Variables: Chronic Pulmonary Obstructive Disease (COPD)

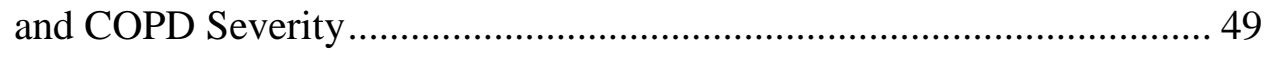

Independent Variable: Exhaled Nitric Oxide...................................................... 50

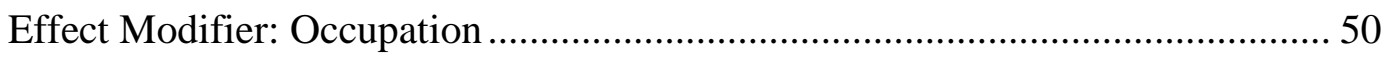

Covariate Variables..................................................................................... 51 


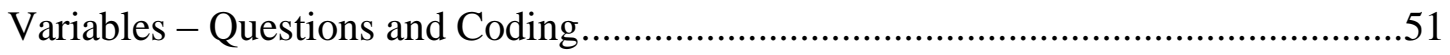

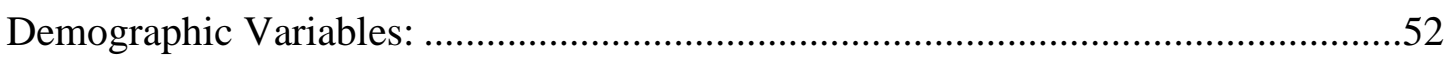

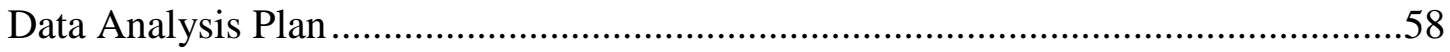

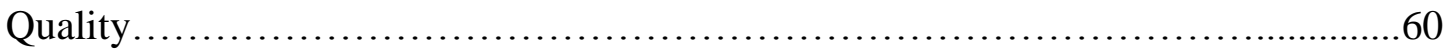

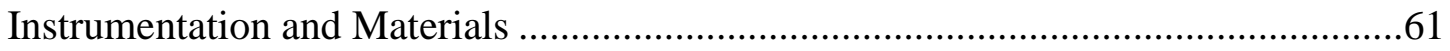

Ethical Considerations and Protection of Human Participants ................................662

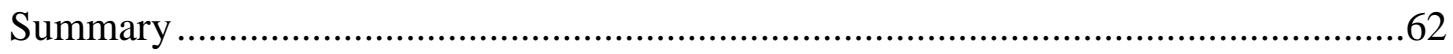

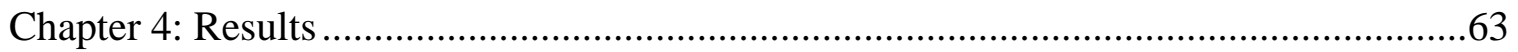

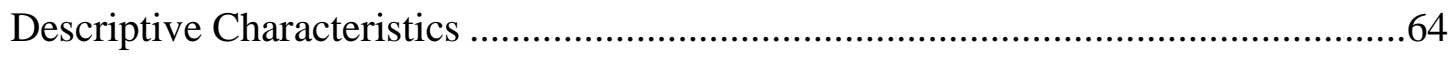

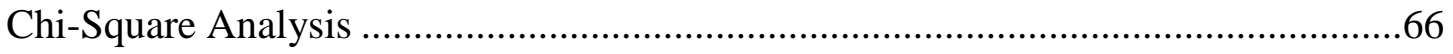

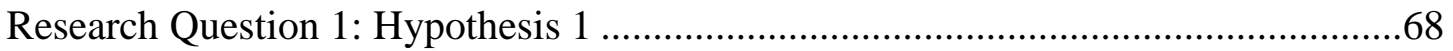

Research Question 1: Hypothesis 2 ............................................................69

Research Question 2: Hypothesis 3 ............................................................... 71

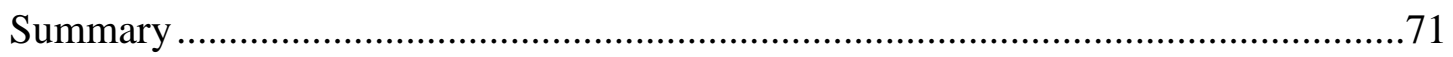

Chapter 5: Discussion, Conclusions, and Recommendations, ...................................73

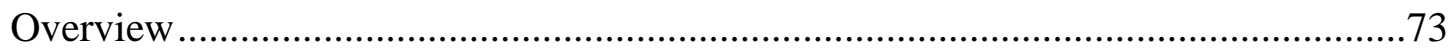

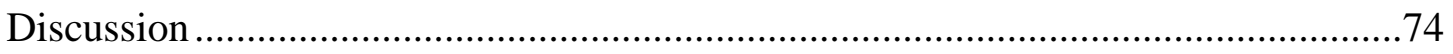

Research Question 1: Is There is an Association Between eNO and COPD

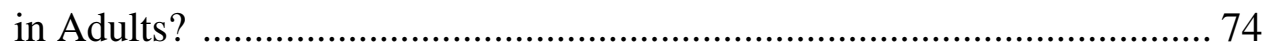

Research Question 2: Does Occupation Modify the Association between

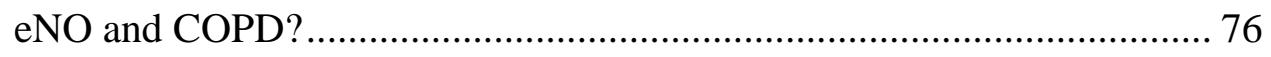

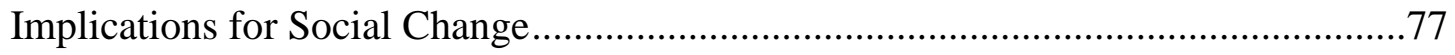




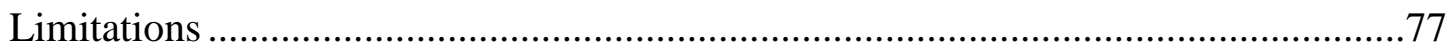

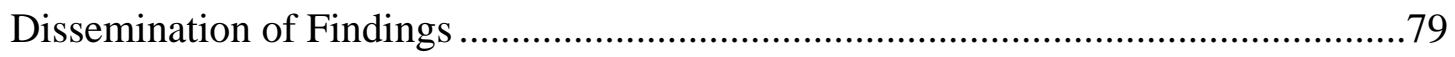

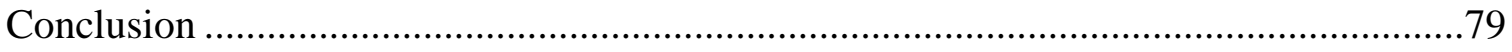

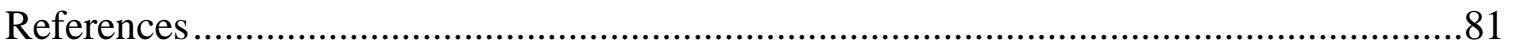

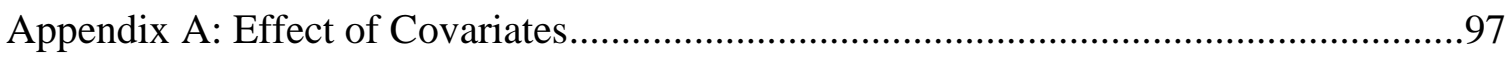

Appendix B: New NHANES Sampling Methodology ....................................................98

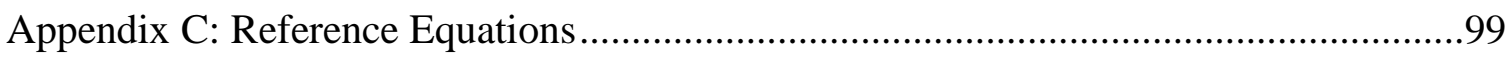

Curriculum Vitae - Colin Mitchell ..........................................................................100 


\section{List of Tables}

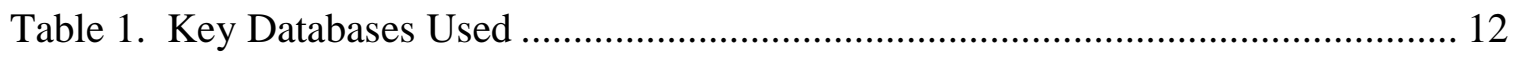

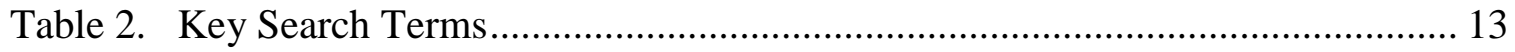

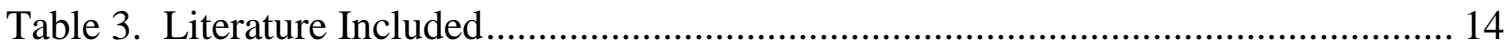

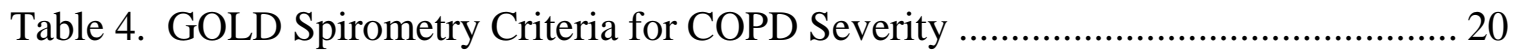

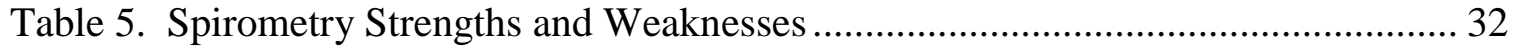

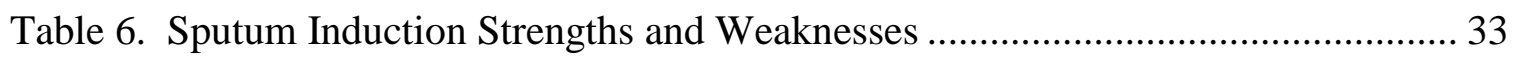

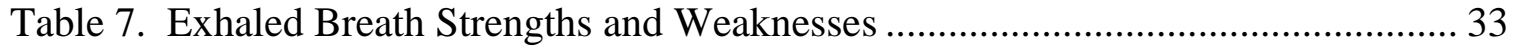

Table 8. Demographic Data - Description and Coding ........................................... 52

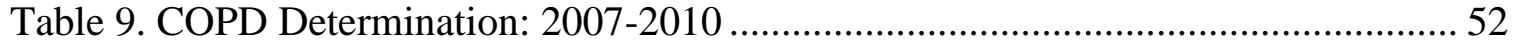

Table 10. COPD Severity Determination: 2007-2010 …........................................... 53

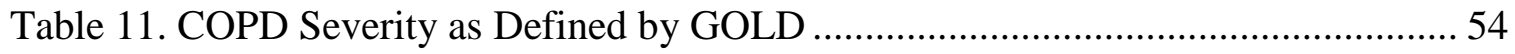

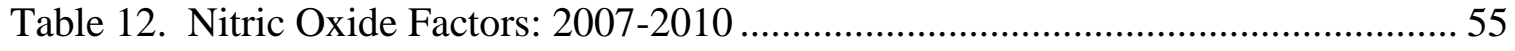

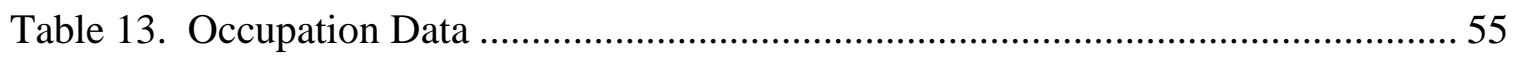

Table 14. Covariate Confounding Questions for Nitric Oxide ................................... 56

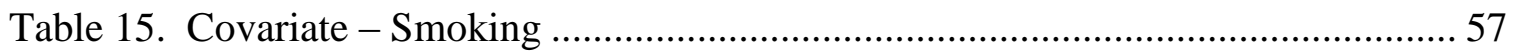

Table 16. Covariate - Body Mass Index (BMI) ….............................................. 58

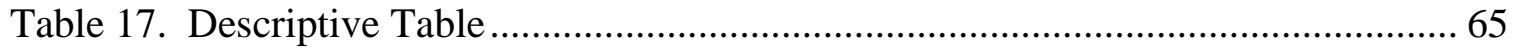

Table 18. Chi-Square Analyses for the Association Between Various Independent

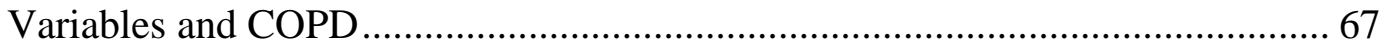

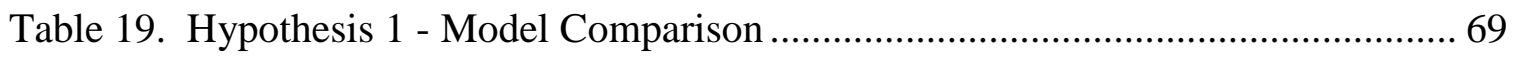

Table 20. Hypothesis 2 - Pre-bronchodilator Spirometry Results .............................. 70 
Table 21. Hypothesis 3- Association Between Nitric Oxide and COPD Stratified by At-

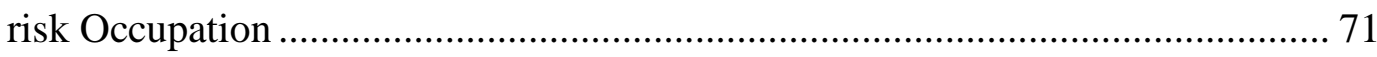




\section{List of Figures}

Figure 1. Hypothesis 1: There is an association between eNO and COPD (chronic bronchitis and emphysema).

Figure 2. Hypothesis 2: Increasing eNO levels are associated with increased COPD severity, as defined by the GOLD standard.

Figure 3. Hypothesis 3 - The association of eNO and COPD is modified by occupational exposure. 16 
Chapter 1: Introduction to the Study

Background of the Study

Chronic Obstructive Pulmonary Disease (COPD) is a leading cause of mortality and morbidity throughout the world. While many medical causes of death are decreasing, COPD is on the rise. In 2005, $5 \%$ of all deaths worldwide were due to COPD complications (World Health Organization, 2011). This percentage is predicted to increase by $30 \%$ by 2020 , and COPD is on target to become the third leading cause of death worldwide (World Health Organization, 2011).

COPD comprises two subgroups of disease: chronic bronchitis and emphysema. Since there is no cure for COPD, the focus is on early diagnosis, treatment, and prevention. The two main methods for diagnosing COPD are spirometry and sputum induction tests. Spirometry determines lung function as a ratio of expired air and lung function, and the sputum test analyzes bacteria and fungi to help establish the stage of the disease. Although both are considered noninvasive, neither is suited for outpatient testing. Sputum induction is too time-consuming-it takes 30 to 45 minutes to complete, requires a lab analysis, and depends upon the patient's ability to produce a sputum sample at the time of testing. Spirometry testing requires a trained medical professional to administer and read the results. One promising technique for use in outpatient settings measures is exhaled breath condensate (EBC) using GC-MS, eNose, or similar methods. The advantage of these methods is that mediators found in exhaled breath, such as exhaled nitric oxide (eNO), may correlate with airway inflammation and disease progression in COPD. If eNO is associated with COPD, then methods could be 
developed to test eNO in outpatient settings, providing public health professionals an important and inexpensive tool to diagnose the type and possibly level of COPD severity.

Airway inflammation is a hallmark of COPD and asthma. Nitric oxide (NO) is naturally produced in the body and helps fight inflammation. Elevated NO levels observed in the EBC of asthmatic patients are used to diagnose and manage asthma in clinical settings (Djukanovic \& Gadola, 2008). However, the role eNO plays in COPD is inconclusive, with some studies finding a positive correlation (Brindicci et al., 2005), others reporting a negative association (Beg, Alzoghaibi, Abba, \& Habib, 2009), and some finding none (Bazeghi, Gerds, Budtz-Jørgensen, Hove, \& Vestbo, 2011). This study took a different approach from current research and analyzed combined data from NHANES 2007-2008 and 2009-2010 to determine associations between eNO, COPD (chronic bronchitis or emphysema), and COPD severity. Patients' occupations are seldom reported in the current literature examining the association between eNO and COPD (Bazeghi et al., 2011; Bhowmik, Seemungal, Donaldson, \& Wedzicha, 2005; Brindicci et al., 2005; Lehouck, Carremans, De Bent, Decramer, \& Janssens, 2010; Liu, Sandrini, Thurston, Yates, \& Thomas, 2007). Therefore, in this study, I also examined whether occupation modifies the association between eNO and COPD. More information is provided in Chapter 2.

\section{Problem Statement}

COPD is often under- or misdiagnosed in the primary care setting (Jochmann et al., 2010; Lehouck et al., 2010; Smidth, Sokolowski, Kærsvang, \& Vedsted, 2012; Spyratos, Chloros, \& Sichletidis, 2012). Spirometry, the current gold standard for 
diagnosing COPD, is often underutilized or used incorrectly (Spyratos et al., 2012). Therefore, a noninvasive method to diagnose COPD in primary care settings is needed. $\mathrm{NO}$ analysis from $\mathrm{EBC}$ is a promising technique which is quick, easy to use, and highly reproducible (Beg et al., 2009).

NO and NO derivatives are known markers of airway inflammation present in EBC of asthma patients. However, studies on the correlation between NO derivatives, airway inflammation, and COPD severity are inconclusive; some have shown an association between eNO and COPD (Beg et al., 2009; Brindicci et al., 2005), whereas others have not (Bazeghi et al., 2011). If eNO levels correlate with inflammation and COPD severity, their measurement would allow public health and clinical professionals to use eNO levels to quickly diagnose COPD severity in outpatient settings. This method is noninvasive and requires less time and expertise than either sputum induction tests or spirometry. Public health professionals agree that a noninvasive method based on EBC is needed for outpatient settings (Fens et al., 2009; Holz et al., 2008). Associating eNO with airway inflammation in COPD would be a step in that direction.

\section{Purpose of the Study}

The purpose of this quantitative study was to determine if there is an association between eNO, COPD subgroups, and COPD severity, using the NHANES 2007 to 2010 data. In addition, I explored effect modification by occupational status. COPD and COPD severity, as defined by the Global Initiative for Lung Disease (GOLD) standard, were dependent variables. Exhaled NO was the independent variable. Exhaled NO is a marker for inflammation in exhaled breath condensate for asthma, but has not been 
proven conclusively to be a marker for airway inflammation in COPD studies. As previously stated, Beg et al. (2009) and Brindicci et al. (2005) have shown a correlation, and Bazeghi et al. (2011) showed none. (Detailed information on these and other studies is presented in Chapter 2.) One major limitation of past studies was low sample size: the average sample size was 80 (range: 20 to 176) with an average of 53 COPD participants in each study (range: 14 to 91). A second limitation is that no researchers have yet examined the possible modifying role of occupational status upon both eNO and COPD. NHANES collected information on self-reported chronic bronchitis and emphysema and measured $\mathrm{FEV}_{1}, \mathrm{FVC}$, and eNO from a large representative sample during its 2007 to 2010 data collection cycles. The presence of these data along with self-reported occupational history provided the opportunity to study the association between eNO, COPD, and COPD severity in a single study. The measurement of eNO in EBC is noninvasive and quick and easy to perform. If it is positively correlated with COPD, it has the potential to replace sputum tests for diagnosis and management.

\section{Theoretical Framework}

This dissertation was guided by the hypothetico-deductive theory, which is based on formulating and testing a hypothesis or hypotheses by deduction analysis (Ludan, 1982). These deductions are tested in controlled experiments. Hypotheses that are falsified are rejected and replaced by new hypotheses. The hypothetico-deductive theory has been around for hundreds of years and tested and debated by such historical figures as Rene Decartes, David Hume, and Issac Newtown (Ludan, 1982). Detailed information on the theoretical framework is presented in Chapter 2. 


\section{Research Questions and Hypotheses}

I examined the associations between eNO, COPD, and COPD severity and the

effect of the role of occupation on these associations. The research questions and the hypotheses for the study were as follows:

- Research Question 1: Is there an association between eNO and COPD (chronic bronchitis or emphysema) in adults?

- Hypothesis 1: There is an association between eNO and self-reported, physician-diagnosed COPD (defined as presence of chronic bronchitis or emphysema) among adult NHANES 2007 to 2010 participants.

○ Hypothesis 2: Increasing eNO levels are associated with increased COPD severity, as defined by the GOLD standard.

- Research Question 2: Does occupation modify the association between eNO and COPD?

$\circ$ Hypothesis 3: The association between NO and COPD is modified by occupation. 


\section{Definition of Terms}

- Chronic Obstructive Pulmonary Disease (COPD): COPD is a slowly progressive, preventable, treatable heterogeneous, multiphenotypic disease that is characterized by limitations of airflow due to inflammation that are not fully reversible and not curable (Basanta et al., 2010; Ferrara, 2011; Garvey, 2011; WHO, 2011). Alternative names for COPD include chronic obstructive airway disease, chronic obstructive lung disease, chronic bronchitis, emphysema, and bronchitis chronic (MedlinePlus, 2011). However, chronic bronchitis and emphysema are the major forms of COPD.

- Exhaled breath condensate (EBC) collection: EBC collection is a noninvasive means to collect breath samples from the lungs. There are many types of mediators within the lungs that are causes of disease and can be regulated by therapeutics (Horváth et al., 2005).

- Global Initiative for Chronic Obstructive Lung Disease (GOLD): The GOLD standard defines four stages of COPD ranging from mild (Stage I) to severe (Stage IV). Each stage is characterized by the airflow limitations calculated by spirometry. A patient classified as Stage I may not be able to sense an abnormal airflow, whereas a person with Stage IV may have chronic respiratory failure and terminal exacerbations. More information is given in Table 4.

- Nitric Oxide (NO): There are several derivatives of NO. Fractional exhaled nitric oxide (FENO) in exhaled breath allows public health professionals to assess airway inflammation. Other derivatives include alveolar nitric oxide concentration 
(CalvNO) and bronchial nitric oxide concentration (JawNO) (Lehouck et al.

2010). I use exhaled nitric oxide (eNO) to represent exhaled nitric oxide, including FENO.

- Spirometry: This method compares the amount of air a person can forcibly exhale in the first second of one breath $\left(\mathrm{FEV}_{1}\right)$ with the amount of total air exhaled in one breath (FVC). The normal $\mathrm{FEV}_{1} / \mathrm{FVC}$ ratio is 70 to $80 \%$ (GOLD, 2010).

- Sputum induction: This is a noninvasive method in which sputum (a combination of mucus and saliva) is expelled from the lungs with the help of a nebulizer. The sputum is then collected and analyzed for disease biomarkers (Grant, Hammitt, Murdoch, O'Brien, \& Scott, 2012).

\section{Assumptions and Limitations}

The NHANES public use data were used in the study, and it was assumed that the sample is representative of noninstitutionalized adults in the United States. It was further assumed that the data — self-reports, $\mathrm{FEV}_{1}, \mathrm{FVC}$, and eNO—were collected according to the established guidelines without any measurement error. Lastly, it was assumed that eNO levels reflect true underlying airway inflammation.

One of the limitations of this study is that self-reported data from the interviews may be subject to recall bias. This bias may be introduced into the study if the patients do not accurately recall reporting information related to certain confounding variables affecting NO levels, such as eating nitrogen-rich foods, smoking, and taking medications. In addition, misclassification bias due to measurement error in administering the spirometry and measuring eNO is also possible. However, it is believed that this bias was 
minimized by the rigorous collection and recording procedures adopted by the NHANES survey. Lastly, self-reported occupation data did not have sufficient detail to determine the potential or actual amount of occupational exposure to harmful particles, gases, and fumes to quantify eNO.

\section{Significance of the Study}

The study has several positive public health implications. The first is that COPD is often misdiagnosed or underdiagnosed in primary care settings (Jochmann et al., 2010; Lehouck et al., 2010; Smidth et al., 2012; Spyratos et al., 2012). Early diagnosis can slow or stop the disease progression by convincing the patient to alter habits, behaviors, or lifestyle, such as quitting smoking (Jochmann et al., 2010; Minas et al., 2010). Currently there is no noninvasive technique that is quick and easy to use in outpatient settings. The availability of noninvasive diagnostic methods could help field medical professionals such as those in mobile health units to reach out to the underserved population, especially in developing countries, to provide and monitor medical care. Early diagnosis of COPD could help decrease the incidence and prevalence of later stage COPD and ultimately could decrease comorbidities and mortality rates caused by COPD.

Measuring eNO in EBC is a promising noninvasive method that would allow physicians and public health professionals to monitor the progression of COPD in outpatient settings with minimal training. 


\section{Implications for Social Change}

The implications for positive social change were that individuals can be diagnosed with a noninvasive method more quickly and safely than with traditional methods. Used in preventative screenings, such a method could result in early diagnosis and treatment to prevent the severe later stage forms of COPD. Patients' quality of life will increase, associated comorbidities will decrease, and mortality rates will decline.

\section{Summary and Transition}

Sputum induction is the current gold standard for determining phenotypes of COPD. However, sputum induction is too time-consuming and labor intensive for use in outpatient settings. Researchers agree that a new noninvasive method is needed for the clinical setting (Jochmann et al., 2010; Lehouck et al., 2010; Smidth et al., 2012; Spyratos et al., 2012). Although gas chromatography-mass spectrometry (GC-MS), electronic noses (eNoses), and similar devices can differentiate between different respiratory diseases such as asthma and COPD, there is no current EBC diagnostic technology that can uncover COPD heterogeneity. In addition, studies correlating eNO to inflammation and COPD severity have been inconclusive as seen in conflicting results from several studies (Bazeghi et al., 2011; Brindicci et al., 2005).

Therefore, in this study, I attempted to improve upon past research by analyzing eNO levels and comparing them with diagnoses of chronic bronchitis and emphysema and documented levels of severity in a larger sample size obtained through NHANES data from 2007 to 2010. In addition, through the second research question, I investigated whether the association between eNO and COPD is modified by occupation. If eNO 
levels are correlated with airway inflammation in different forms of COPD subgroups and severity, the measurement of eNO could be used to develop methods for EBC testing. This could lead to more patients tested in outpatient settings as a preventive measure and eventually could lead to early treatment that would result in a decrease in later-stage COPD cases and COPD-related comorbidities, lower healthcare costs, and eventually a decrease in COPD-related mortality.

In Chapter 2, I review the literature related to eNO and COPD and outline the theoretical framework of this study. The GOLD standard, spirometry, and the role of occupation are also discussed. Chapter 3 outlines the research methodology; describes the dependent, independent, and confounding variables; and explains the statistical analysis. The results of this study are reported in Chapter 4, and the summary, discussion, and conclusions are presented in Chapter 5. 
Chapter 2: Literature Review

\section{Background}

Current methods for diagnosing COPD in the primary care setting, such as spirometry are underutilized, attributing to the misdiagnoses of COPD in primary care (Jochmann et al., 2010; Lehouck et al., 2010; Smidth et al., 2012; Spyratos et al., 2012). Therefore, a noninvasive method that is quick and easy to use is needed. A promising technique is analyzing eNO from EBC. The rationale is that airway inflammation is found in all forms of COPD. NO and NO derivatives are known markers of airway inflammation present in EBC. Research has shown a correlation between eNO and inflammation in asthma patients. However, there is no conclusive association between NO derivatives, airway inflammation, and COPD severity. Therefore, the purpose of this study was twofold. The first objective was to investigate the association between eNO and COPD and eNO and COPD severity using NHANES data from 2007 to 2010. The second was to investigate whether the association between eNO and COPD is modified by occupation. This study used a larger sample size than previous studies and compared eNO, COPD (emphysema, chronic bronchitis), and COPD severity, where most recent research has focused on eNO and COPD or eNO and COPD severity, not both (Beg et al., 2009; Brindicci et al., 2005; Liu et al., 2007). In addition, I investigated whether the association between eNO and COPD is modified by occupation.

I begin this chapter with reviewing basic information on COPD including prevalence and incidence, causes, at-risk population, diagnosis, mortality, and costs. More detailed information follows, with sections on epidemiology; risk factors ranging 
from tobacco use to genetics; symptoms; and exacerbations. I continue with detailed sections on methods for diagnosis such as sputum induction, spirometry, and EBC. I conclude with general information on NO leading into a more detailed discussion on the association between eNO and COPD (chronic bronchitis, emphysema), eNO and COPD severity, and NO from occupational exposure. Table 1 gives the key databases used, and Table 2 lists key search terms.

\section{Literature Search Strategy}

Table 1

Key Databases Used

Key Databases Used

Walden University Library - Thoreau

Walden University Library - Medline with Full Text

Walden University CINAHL Plus with Full Text

Google: Google Scholar

Google: Google Search Engine 
Table 2

Key Search Terms

Search terms

- Chronic Bronchitis

- Chronic Obstructive Pulmonary Disease

- Chronic Obstructive Pulmonary Disease, by country

- Chronic Obstructive Pulmonary Disease, Costs

- Chronic Obstructive Pulmonary Disease, EBC

- Chronic Obstructive Pulmonary Disease, Epidemiology EBC

- Chronic Obstructive Pulmonary Disease, Specific Author Name Exhaled Breath Condensate

- COPD

- COPD, Costs

- $\mathrm{COPD}, \mathrm{EBC}$

- COPD, Europe

- COPD, Exhaled Breath Condensate

- COPD, NHANES

- COPD, NO, NHANES

- Diagnosis, COPD

- Diagnosis, Chronic Obstructive Pulmonary Disease

- Emphysema

- Epidemiology COPD, Specific Author Name

- GOLD, Chronic Obstructive Pulmonary Disease

- GOLD, COPD

- NHANES, Nitric, COPD, Occupation

- NHANES, Nitric, COPD, Job

- NHANES, Nitric, COPD, Work
- Nitric, COPD, NHANES

- Nitric, Job

- Nitric, Occupation

- Nitric, Work

- Nitric Oxide

- Nitric Oxide, Inflammation

- Nitric Oxide, Job

- Nitric Oxide, NHANES

- Nitric Oxide, Occupation

- Nitric Oxide, Work

- Nitric Oxide, Specific Author Name

- NO, COPD, Job

- NO, COPD, Occupation

- NO, COPD, Work

- NO, Inflammation

- NO, NHANES

- NO, Nitric

- NO, Specific Author Name

- Specific Author Name

- Specific Title of a Paper

- Spirometry

- Sputum Induction 


\section{Scope of Literature}

The literature collected was published from 1995 to 2014. Research from 1995 to 2005 was used to provide a historical background and to frame the problem. Most data came from recent literature dating from 2005 to 2014. Assessing the link between eNO and COPD is a relatively new topic, and current literature was limited in the number and size of the studies. Literature included in this study is from peer-reviewed sources, scholarly articles, periodicals, journals, textbooks, websites, interviews, conferences, and Internet sources. Table 3 gives examples of literature collected and analyzed for this paper.

Table 3

Literature Included

\begin{tabular}{ll}
\hline Sources & Examples \\
\hline Conferences & Breath Summit 2011 \\
Internet sources & $\begin{array}{l}\text { Center for Disease Control, World Health } \\
\text { Organization }\end{array}$ \\
Interviews & Dr. Susan Hausserman \\
Journals, peer-reviewed sources, & American Journal of Respiratory Care \\
Periodicals & Medicine \\
Scholarly articles & Journal of Breath Research \\
Textbooks & $\begin{array}{l}\text { Health promotion planning and evaluation: } \\
\text { A practical, systemic approach for } \\
\text { community health }\end{array}$ \\
\hline
\end{tabular}




\section{Theoretical Framework}

The hypothetico-deductive theory is based on formulating and testing a hypothesis or hypotheses by deduction analysis. Deductions are tested by observations and experiments. Hypotheses that are proven false are rejected and replaced by new hypotheses (Oreskes, 2003). Figures 1, 2, and 3 are visual representations of the three hypotheses in this study.

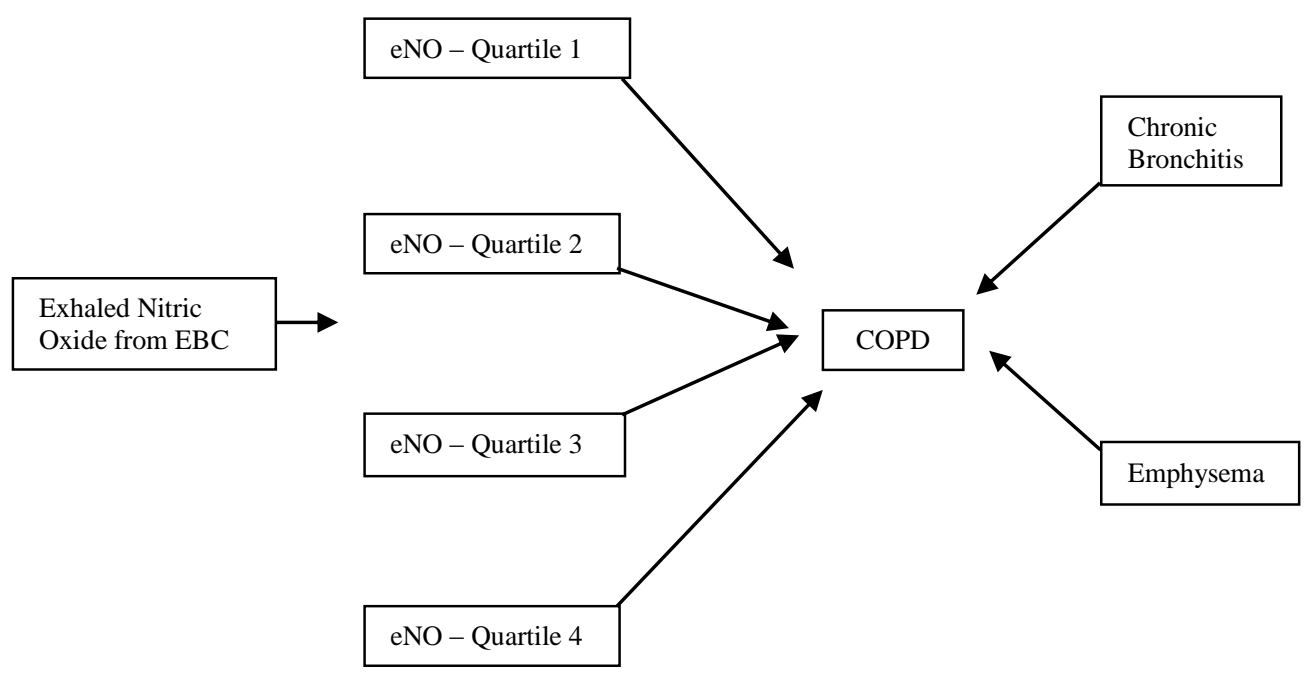

Figure 1. Hypothesis 1: There is an association between eNO and COPD (chronic bronchitis and emphysema). 


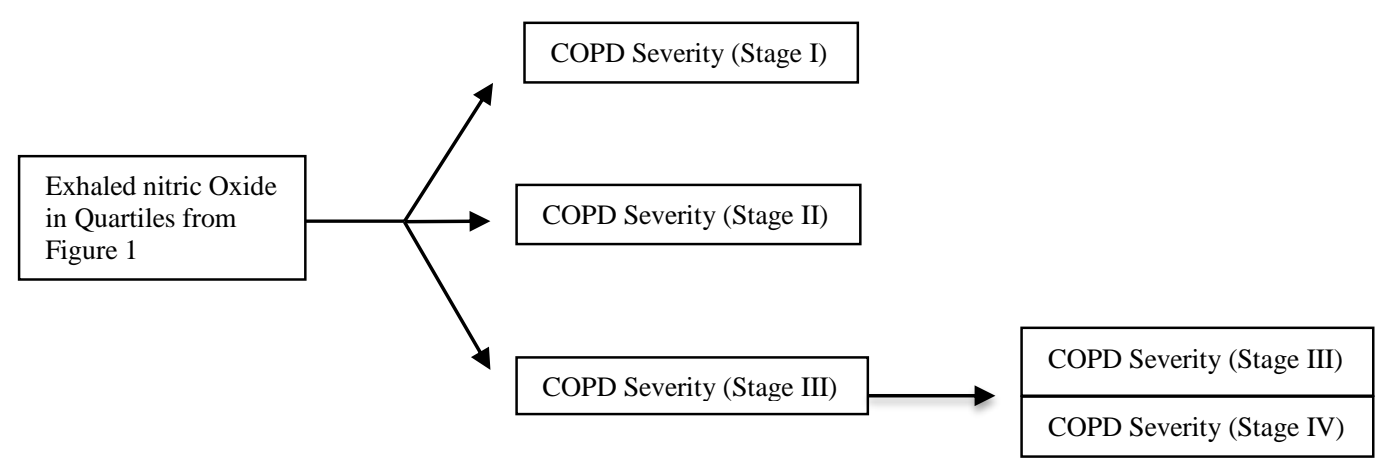

Figure 2. Hypothesis 2: Increasing eNO levels are associated with increased COPD severity, as defined by the GOLD standard.

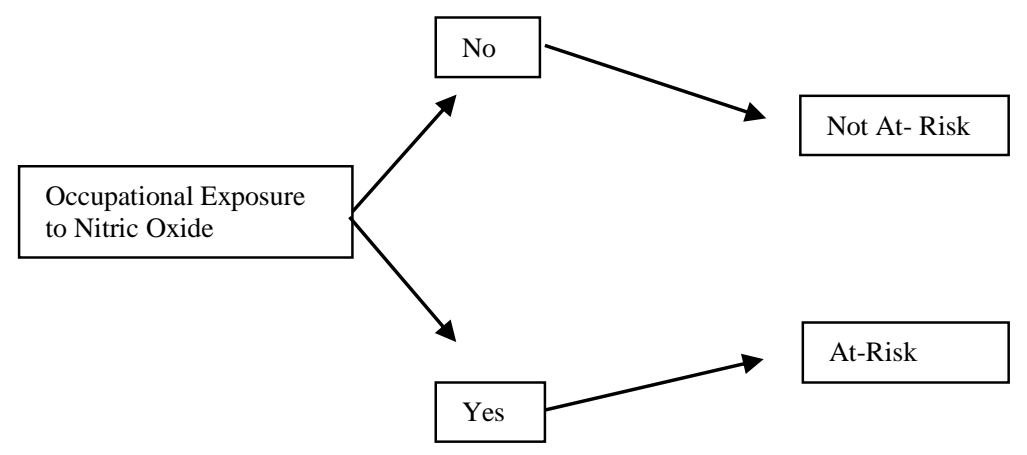

Figure 3. Hypothesis 3 - The association of eNO and COPD is modified by occupational exposure.

Exhaled NO is a determinant of airway inflammation in asthma, and airway inflammation is prevalent in all stages of COPD. Therefore, eNO may be a determinant of airway inflammation for COPD, and eNO could be used as a noninvasive biomarker to diagnose COPD. This is important, because this is a noninvasive, easy-to-use method that could replace more invasive tests. 
The independent variable was eNO. The first hypothesis stated that eNO was associated with COPD. The second hypothesis stated that there is an association between eNO and COPD severity as categorized by the GOLD standard. Exhaled NO is a known marker for airway inflammation in asthma, but its role in COPD is inconclusive. Through the second research question, I investigated whether occupation modified the association between eNO and COPD.

\section{Introduction}

COPD is a global disease contributing to an increase in morbidity and mortality while causing higher medical costs and social economic burdens (Budweiser et al., 2007; Rocker, Young, \& Simpson, 2009; Tonello \& Poli, 2011). In 2002, COPD was the fifth leading cause of death (Tonello \& Poli, 2011; World Health Organization, 2011). In 2004, COPD affected approximately 64 million people (World Health Organization, 2011). In 2005, $5 \%$ of deaths worldwide (3 million people) resulted from COPD (World Health Organization, 2011). Ninety percent of COPD-related deaths were in low-income to middle-income countries (World Health Organization, 2011). Total deaths are expected to rise by $30 \%$ over the next decade if there are no interventions. Furthermore, COPD is expected to become the third leading cause of death globally by 2020 (Bessa et al., 2011; Rocker et al., 2009; World Health Organization, 2011). This projected increase in mortality is due to the aging of the world's population and the continued use of tobacco (Malipatil \& McDonald, 2009). In Western societies, many medical causes of death are on the decline; however, the prevalence of morbidity and mortality of COPD in both men and women is increasing (Rocker et al., 2009). 
COPD is a noncurable, slowly progressive, preventable but treatable heterogeneous, multiphenotypic disease that is characterized by limitations of airflow due to inflammation (Basanta et al., 2010; Garvey, 2011; World Health Organization, 2011). Alternative names for COPD include chronic obstructive airway disease, chronic obstructive lung disease, chronic bronchitis, emphysema, and bronchitis chronic (MedlinePlus, 2011). However, chronic bronchitis and emphysema are the two dominant forms of COPD, and most people have a combination of the two.

COPD is not fully reversible, and therefore the focus is not on curing the disease, but on diagnosis, prevention, and treatment. Two major risk factors for COPD include tobacco smoke and air pollutants (Hoth, Wamboldt, Bowler, Make, \& Holm, 2011). For example, in the United States, smoking played a role among $80 \%$ to $90 \%$ of COPD patients (Hoth et al., 2011). Although COPD is prevalent in smokers, research has shown that nonsmokers can also develop it because of genetic disposition (Nazir \& Erbland, 2009). Studies have determined that mutations of a specific gene may cause COPD in nonsmokers (Nazir \& Erbland, 2009). COPD affects the entire body, including the heart, kidneys, and muscles, and is associated with a large range of comorbidities, such as cardiovascular disease, osteoporosis, and diabetes (Lynes, 2010). In addition, there are emotional consequences of having COPD, as the patient's quality of life (QoL) is adversely affected. For example, individuals with COPD may experience difficulties in a wide range of areas in their life, resulting in early retirement, financial stress, family complications, changes in self-esteem, and lack of independence (Avsar \& Kasikci, 
2010). In addition, recent studies have demonstrated that oxidative stress is a key risk factor in the pathogenesis of COPD (Lee \& Thomas, 2009).

COPD is a major contributor to death, disability, and financial burdens throughout the world. As the population ages, COPD will continue to contribute to economic hardships for several years (Hutchinson, Brand, Irving, Roberts, \& Campbell, 2010). As the prevalence and incidence rates of GOLD Stages III and IV increase, compared to Stages I and II, the costs of COPD management will also increase. The advanced stages of the disease consume a large proportion of health care resources due to excessive hospitalizations, exacerbations, and mortality rates (Budweiser, Jorres, \& Pfeifer, 2008).

Early diagnosis and treatment are key to controlling and decreasing COPD incidence and prevalence rates. Currently, lung performance is assessed by spirometry, which is accepted as a universal method, by public health professionals worldwide, to test for COPD. This method measures the ratio of $\mathrm{FEV}_{1}$ to $\mathrm{FVC}$. A healthy person has an observed ratio of greater than or equal to $70 \%$ lung capacity. Individuals with a ratio of less than $70 \%$ are considered to have some form of COPD (GOLD, 2010). The GOLD standard lists four stages of COPD, with Stage I defined as mild COPD, and Stage IV as very severe (see Table 4). Due to the slow progressive nature of the disease, COPD is more frequently diagnosed in individuals over 40 years of age (World Health Organization, 2011). However, many forms of treatment are available to aid in managing symptoms and increasing QoL. Pharmacotherapy targeted at COPD includes the use of bronchodilators, corticosteroids, antibacterial products, and/ or a mix of these 
pharmaceuticals (Nazir \& Erbland, 2009). Table 4 gives the criteria for COPD severity when tested by spirometry.

Table 4

GOLD Spirometry Criteria for COPD Severity

\begin{tabular}{|c|c|c|}
\hline Severity & $\begin{array}{l}\text { Characterized by airflow } \\
\text { limitation }\end{array}$ & Criteria \\
\hline Mild (I) & $\begin{array}{l}\mathrm{FEV}_{1} / \mathrm{FVC}<0.70, \mathrm{FEV}_{1} \\
>=80 \% \text { predicted }\end{array}$ & $\begin{array}{l}\text { At this stage, the patient } \\
\text { may not be aware that their } \\
\text { lung function is abnormal. }\end{array}$ \\
\hline Moderate (II) & $\begin{array}{l}\mathrm{FEV}_{1} / \mathrm{FVC}<0.70,50 \% \\
<=\mathrm{FEV}_{1}<=80 \% \\
\text { predicted }\end{array}$ & $\begin{array}{l}\text { Symptoms usually progress } \\
\text { at this stage, with shortness } \\
\text { of breath typically developing } \\
\text { on exertion. }\end{array}$ \\
\hline Severe (III) & $\begin{array}{l}\mathrm{FEV}_{1} / \mathrm{FVC}<0.70,30 \% \\
<=\mathrm{FEV}_{1}<=50 \% \\
\text { predicted }\end{array}$ & $\begin{array}{l}\text { Shortness of breath typically } \\
\text { worsens at this stage and } \\
\text { often limits patients' daily } \\
\text { activities. Exacerbations are } \\
\text { especially seen beginning at } \\
\text { this stage. }\end{array}$ \\
\hline Very Severe (IV) & $\begin{array}{l}\mathrm{FEV}_{1} / \mathrm{FVC}<0.70,<30 \\
\% \text { predicted or } \mathrm{FEV}_{1} \\
<50 \% \text { predicted plus } \\
\text { chronic respiratory } \\
\text { failure }\end{array}$ & $\begin{array}{l}\text { At this stage, quality of life } \\
\text { is very appreciably impaired } \\
\text { and exacerbations may be } \\
\text { life-threatening. }\end{array}$ \\
\hline
\end{tabular}

COPD is underdiagnosed around the world (Jochmann et al., 2010; An Lehouck et al., 2010). For example, in the United States, for every one person diagnosed with COPD, there are another 1.4 people who have not been diagnosed and therefore not captured in healthcare statistics (Garvey, 2011). Concerning healthcare utilization in the United States, in 2000 there are approximately 8 million primary care provider and 
outpatient visits, 1.5 million emergency room visits and 726,000 hospitalizations due to COPD (Garvey, 2011). In addition, 1 in 5 elderly in the United States are hospitalized because of COPD (Avsar \& Kasikci, 2010; Malipatil \& McDonald, 2009). Estimated annual COPD rates in other countries are 2.7 million in Germany, 300,000 in Australia, 200,000 in New Zealand, and 1.5 million in Spain (Avsar \& Kasikci, 2010).

In 2005, COPD caused 126,005 deaths in the United States in persons 25 years and older. This represented an 8\% increase from 116,494 in 2000 (Caress, Luker, \& Chalmers, 2010). The United Kingdom estimates that there are between 25,000 and 30,000 COPD-related deaths per year (British Lung Foundation, 2011; Health and Safety Executive, 2013). Approximately $15 \%$ of those admitted with COPD die within the following 3 months, and 25\% within 1 year of admission (British Lung Foundation, 2011; Trueman \& Trueman, 2011).

Healthcare costs related to COPD have a significant impact throughout the world. In 2001, 520 patients were admitted to UK hospitals. This equates to 4,156 beds or $£ 1.13$ million In Spain, $43.8 \%$ of all hospitalization costs and $40.3 \%$ of drug acquisition costs are related to COPD (Banning, 2006). The cost of treating patients with exacerbated COPD by the Canadian Healthcare system was approximately $\$ 750$ million per year (Rocker et al., 2009). A study on the economic burden in the United States concluded that the cost per patient was between $\$ 2,700$ and $\$ 5,900$ per patient annually. In-patient hospitalization accounted for close to $70 \%$ of all direct costs. One study estimates the total costs due to COPD in the United States at $\$ 10$ billion per year (Rocker et al., 2009). Another estimates direct costs of COPD at \$29.5 billion and indirect costs at $\$ 20.4$ billion 
(GOLD, 2010). The healthcare cost for people with COPD are more than double of those of age-matched peers (Rocker et al., 2009). In Europe, $6 \%$ of total healthcare costs are related to respiratory diseases (Spyratos et al., 2012). COPD accounts for 50\% of those costs - 38.6 billion euros per year(Spyratos et al., 2012).

The COPD drug market is estimated to increase from approximately $\$ 8.4$ billion in 2009 to more than $\$ 13$ billion in 2019 in the US, France, Germany, Italy, Spain, UK, and Japan (Business Wire, 2011). Forecasters believe that an expanding aging population and improvements in diagnosis and drug treatment will drive market growth (Business Wire, 2011). In addition, in the major pharmaceutical markets, the population that will rely on drug treatments will increase $75 \%$, from 18 million patients in 2009 to approximately 24 million in 2019 (Business Wire, 2011).

High healthcare costs are evident before COPD diagnosis. One study, a retrospective analysis of healthcare costs using matched cases and controls, determined that costs were $\$ 1,182$ higher 24 months prior to diagnosis of COPD and $\$ 2,489$ higher 12 months before (Mapel et al., 2008). United States' data for 2001, showed 110,000 deaths, 500,000 hospitalizations, and over $\$ 18$ billion in direct medical expenditures annually as a result of acute exacerbations of COPD (Hutchinson et al., 2010). The implication is that these cost could be prevented or reduced with early diagnosis of COPD.

\section{Epidemiology/ Clinical - Demographics}

COPD is a slow, progressive disease that typically affects people 40 years old and older (World Health Organization, 2011). Men and women are equally affected by 
COPD. The World Health Organization attributes this to an increase in the incidence and prevalence in women smokers in high-income countries (World Health Organization, 2011). A study using NHANES data from 1997 to 2004 showed a high incidence in young women $(5.4 \% 95 \%$ CI: $5.3-5.6)$ compared to men $(2.8 \% 95 \%$ CI: $2.7-2.9)$ validating the hypothesis that COPD is increasing among women (Bang, Syamial, \& Mazurek, 2009).

Emphysema and chronic bronchitis are the two dominant forms of COPD. Emphysema is the destruction of the lung over time by enlargement of and destruction of air sacs (Ferrara, 2011; MedlinePlus, 2011). Some causes for the enlargement include congenital defects, surgical procedures on the lung, or an infection (Ferrara, 2011). The disease process itself centers around inflammatory injury to the lung due to abnormal immune response to products like the toxic particles in tobacco smoke, inhalation of environmental particulates, or occupational exposure to biomass fuel products in poorly ventilated areas. A poor immune response causes the small air-exchange spaces in the lungs to expand and combine into larger, dysfunctional airspaces. This results in a loss of function, a loss of lung elasticity, an increase in hyperinflation, and ultimately, a reduction of airflow in the lungs (Ferrara, 2011). There are several types of emphysema, such as panacinar emphysema and centrilobular emphysema, but each form displays the same destructive patterns (Ferrara, 2011).

Bronchitis is the inflammation of the bronchial tubes. The bronchial walls become permanently inflamed or thickened. This creates a cough that produces mucus or phlegm. Chronic bronchitis is a progressive disease that is defined by coughing at least 
one time a day for 3 months. Complications from chronic bronchitis include asthma, bronchectasis, cystic fibrosis, tuberculosis, and sinusitis.

\section{General Risk Factors}

Risk factors for COPD are outdoor air pollution and indoor air pollution, such as occupational dust and particulate irritants and chemical vapors and fumes (GOLD, 2010). Biomass fuels are a major contributor to COPD among nonsmoking women in countries like Africa and Asia, as well (World Health Organization, 2011). Individuals with frequent lower respiratory infections during childhood are at risk for COPD (GOLD, 2010; MedlinePlus, 2011). Genetics is also a factor in the rare cases of individuals who develop emphysema due to a lack of the protein alpha-1-antitrypsin (MedlinePlus, 2011).

The metabolic and physiological changes of aging can influence efficacy and safety. In order patients, the high prevalence of comorbidities such as cardiovascular disease and osteoporosis can reduce tolerance to COPD therapy. (Malipatil \& McDonald, 2009). In the Burden of Obstructive Lung Disease initiative, the prevalence of COPD GOLD Stage II or higher across 12 countries was $11.8 \%$ for men and $8.5 \%$ for women (Imperial College London, n.d.; Nazir \& Erbland, 2009). Results from this study showed that disease prevalence increases with age. Less than 5\% of all persons aged 40 to 49 had COPD, but the incidence increased $19 \%$ to $47 \%$ and $6 \%$ to $33 \%$ in men and women, respectively, for those aged 70 and over (Nazir \& Erbland, 2009).

Another risk factor is exposure to certain environmental conditions during childhood. Depending on the type of pollutant and the amount inhaled, children may have the same level of risk as smokers (Ferrara, 2011). In addition, maternal smoking has 
been associated with the development of respiratory diseases (including COPD) in adults (Ferrara, 2011).

COPD rates in the United States are inversely proportional to socioeconomic status, with blue-collar workers exhibiting higher degrees of mortality and morbidity rates than white-collar workers (Ferrara, 2011). Individuals who work on a farm are constantly exposed to dust and are two to three times more likely to develop COPD than non-farm workers. Coal miners also have an increased risk due to their working environment (Ferrara, 2011). These same disparities are apparent when comparing education and income (Ferrara, 2011). The risk of developing COPD during adulthood may be linked to lower socioeconomic status during childhood, resulting from to exposure to outdoor and indoor pollution (Nazir \& Erbland, 2009).

Genetic studies have looked at the association of polymorphism and COPD. A meta-analysis study on 20 polymorphisms in 12 candidate genes showed that many genes were not linked to COPD. However, the study populations included in the sample influenced this result (Cosio \& Agusti, 2010). In addition, a study linking the C-reactive protein gene to COPD has been inconclusive. Therefore, evidence linking genetic inheritance and COPD is currently inconclusive, and further research is needed (Cosio \& Agusti, 2010).

\section{Symptoms}

Symptoms of COPD include abnormal sputum (a mixture of mucus and saliva the airway), breathlessness, and a chronic cough. Other symptoms include mucus produced when coughing, shortness of breath (dyspnea) that worsens even with minimal activity, 
presentation of respiratory infections, and wheezing (MedlinePlus, 2011). Daily activities like walking upstairs can become difficult as the disease worsens (World Health Organization, 2011). Other problems include increased anterior and posterior chest diameter-AKA "barrel chest" — caused by air trapping; cyanosis; nail clubbing: and the use of accessory muscles when breathing (Ferrara, 2011). COPD patients may not experience all of these symptoms. For example, in one study $43 \%$ of patients did not produce sputum (Lynes, 2010; Zieliñski, Bednarek, \& Group, 2001). Since COPD is progressive, the disease is often undetected; patients are not aware that they are sick. The first indication of COPD may be when the symptoms worsen; increased quantities of sputum, sputum purulence, and shortness of breath (dyspnea) are signs that the patient has an exacerbation at a more advanced stage of the disease (Albertson, Louie, \& Chan, 2010; MedlinePlus, 2011; Stoloff, 2011). More specifically, these are signs of acute exacerbations of chronic bronchitis (Albertson et al., 2010; Lynes, 2010; MedlinePlus, 2011). However, COPD is a heterogeneous disease and can be difficult to diagnosis.

Exacerbation is an acute action resulting in a deviation in the individual's dyspnea, cough, or sputum production from the norm and requires a change in regular treatment (Garvey, 2011; Nazir \& Erbland, 2009). Exacerbations of COPD decrease QoL and lung function (Garvey, 2011). These exacerbations are interconnected and are associated with increased morbidity, increased comorbidities, decreased physical health, and increased chances of premature mortality (Glaab, Vogelmeier, \& Buhl, 2010). However, comparing clinical symptoms of different patients can be challenging, because there are no standard definitions of exacerbations (Glaab, Vogelmeier, \& Buhl, 2010; 
Nazir \& Erbland, 2009). In addition, exacerbations can be underreported due to recall and selective bias by patients (Glaab et al., 2010). Contributors to acute exacerbations include exposure to air pollution from particulates of diesel, sulfur dioxide, ozone, and nitrogen (Nazir \& Erbland, 2009). Other risk factors include age, decreases in $\mathrm{FEV}_{1}$, lung infection, and high frequencies of past exacerbations (Albertson et al., 2010; Nazir \& Erbland, 2009). Seventy-five percent of cases of acute exacerbations are caused by viral, bacterial, or mixed viral-bacterial changes (Albertson et al., 2010). Research indicates that these exacerbations are semirandom. This means that the exacerbations are unpredictable but tend to cluster in time. For example, after a patient is subject to a first exacerbation, then the chances of a second exacerbation are greatly increased (Cosio \& Agusti, 2010).

\section{Methods for Diagnosis}

Due to the wide range of comorbidities and the progressive nature of COPD, researchers have focused on early diagnosis, prevention, and treatment. There are invasive approaches to determine airway inflammation, such as bronchoscopy and brancholveolar lavage, but these have been complemented by or replaced by the noninvasive method of induced sputum analysis (more information in the next section). However, the limitations of the induced sputum method have led researchers to consider alternative methods, such as EBC sampling. Current methods for testing airway inflammation include spirometry to analyze lung function and sputum induction to determine airway inflammation. 
Spirometry is performed by having the patient blow into a handheld device that measures lung capacity. Trained medical personnel can interpret the test results directly without the patient having to exercise, draw blood, or be exposed to radiation (MedlinePlus, 2011). This is one of the most important tests for determining COPD severity levels; it is both accurate and reliable (Garvey, 2011). Even though the method is considered the gold standard for measuring COPD progression, the procedure is underused or used inconsistently in the clinical setting (Stoloff, 2011). For example, several studies assessed the use of spirometry in patients hospitalized and then discharged with a diagnosis of COPD (Stoloff, 2011). Only 31\% of these patients were tested using spirometry over an 8-year period (Stoloff, 2011). Studies in Germany, Switzerland, and Denmark found that spirometry testing was underutilized when diagnosing COPD, leading to the underreporting of the disease (Jochmann et al., 2010; Smidth et al., 2012). In addition, other countries with good healthcare such as the United States, Spain, and Italy, also reported under usage of spirometry (Spyratos et al., 2012).

Spirometry is one of the most important analysis for the diagnoses of COPD. The GOLD standard suggests a bronchodilator rate of $\mathrm{FEV}_{1} / \mathrm{FVC}<70 \%$ diagnostic for COPD. A limitation is that the $\mathrm{FEV}_{1} / \mathrm{FVC}$ ratio naturally declines with age, and using a fixed ratio increases the risk of over-diagnosing COPD in the elderly. Factors contributing to over-diagnosis include reduced perception of airflow, tendency to attribute symptoms to aging process, and lack of spirometric testing (Malipatil \& McDonald, 2009). In clinical practice this risk is offset by underdiagnoses in older people (Malipatil \& McDonald, 2009). 
Sputum induction is a primary analytic tool for the study of airway inflammation (Djukanovic, 2000). Sputum culture is used to detect and identify bacteria or fungi that are affecting the lungs or breathing passages (WebMD, 2012; 2011). One of the benefits of using induced sputum is the safety of the method; it is easy to use given time but depends on the severity of the disease and the patient's ability to produce sputum at home (Djukanovic, 2000; Holz et al., 2008). A second benefit is that sputum induction does not require expensive equipment and testing is generally reimbursed by insurance (Holz et al., 2008). Third, sputum induction results in a more representative sample of several proximal airways than other methods (Djukanovic, 2000). Limitations include high levels of thick mucus in unprocessed sputum (Djukanovic, 2000). Samples are of lower quality of induced sputum and smear slide samples provide only semiquantitative information (Holz et al., 2008). The induction process of sputum is not suited to the outpatient setting because the method is labor intensive, depending on the patient ability to produce sputum, and the method is time consuming (Holz et al., 2008).

Spirometry is the current benchmark for determining COPD, and sputum induction can identify bacteria and/ or fungi affecting the lungs. However, there are limitations to both methods (Tables 5-6). A promising area of research is using EBC to differentiate between different respiratory diseases and between phenotypes of the same disease. Two studies published in 2011 use EBC to differentiate COPD patients who were smokers from those who were nonsmokers. An eNose was used in both studies to analyze EBC from patients. One study was able to differentiate between asthmatic patients and those with COPD but unable to identify different stages of COPD by EBC 
alone (Holz, Zesiger, Lavaue-Mokhtari, Schuchardt, \& Hohfeld, 2011). This study, which had a small sample size of 14 patients, concluded that evaluating exhaled breath profiles by eNose has the potential to become a widely used noninvasive diagnostic tool. In the same year another study, using 100 patients, was able to differentiate between COPD and non-COPD patients. The study conducted in the Netherlands used 100 patients, a Tedlar bag sample collection system, and an eNose (Fens et al., 2011; Fens, Roldaan, Zwinderman, Bel, \& Sterk, 2011). However the conclusion also mentioned that a more sensitive method and further research is necessary to show phenotypic differences (Fens et al., 2011; Fens, Roldaan, Zwinderman, Bel, \& Sterk, 2011). Both 2011 studies state that EBC is a promising method for noninvasive analysis of some respiratory diseases. Other researchers have used a wide variety of tools to diagnose EBC—eNoses with varying sensitivities, ion mobility spectrometers, differential mobility spectrometry, GCMS, and gas sensory array technology, to name a few. With the exception of an eNose application published in 2009, none have been able to uncover the heterogeneity of COPD. The 2009 study (Velásquez, Durán, Gualdron, Rodriguez, \& Manjarres, 2009) distinguished between phenotypes, but the results were subjective because the classification of phenotypes was done by a personal physician and were not reproducible.

\section{Exhaled Breath Condensate}

To date, researchers have identified more than 3,500 components (mixtures of gases and volatile organic compounds) in exhaled breath (Popov, 2011). Almost half of the volatile organic compounds originate from within the body, and approximately 200 trace compounds can be detected and quantified in an average human breath (Popov, 
2011). The compounds can vary due to diet or disease. One of the most well-known examples of breath analysis is ethanol analysis, used to check for alcohol consumption levels. Other successful clinical applications include linking NO levels to asthma and linking carbon monoxide to oxidative stress (Popov, 2011).

Using EBC for collecting and analyzing biomarkers has several advantages-ease of use, noninvasiveness, the possibility of repeated sampling, and suitability for use with children and patients with severe disease (Koczulla et al., 2009). In addition, samples can be collected in a portable device home (Koczulla et al., 2009).

One limitation of using EBC for COPD determination is its variability in statistical analysis. There are several algorithms used to draw correlations between EBC and respiratory diseases - specifically, asthma and COPD. The results are more or less favorable depending on the algorithm used. Therefore, researchers tend to use algorithms that portray the data in the best possible manner. Standardization is necessary to be able to compare data from one study to another. A second limitation is that there is no standard or accepted method for EBC analysis. Several techniques have been used, including various eNoses, mass spectrometers, combination GC-MS, ion mass spectrometers (IMS), proton transfer reaction-mass spectrometers (PTR-MS), and gas sensor arrays. No one method out-performs the others, although PTR-MS and IMS show promise. The limitation is that comparing data with different types of diagnostic devices is challenging without standardized methods. This is further complicated when comparing different diagnostic equipment with different algorithms. A third limitation is the lack of standardization of a sampling technique. Collection techniques range from 
having the patient breathe one time into a Tedlar bag to sampling using PTR-MS, where the PTR-MS and the patient must be present at the same time and breath is collected over a given period of time, such as ten minutes. The difficulty is in knowing which part of the lung (lower, middle, or upper regions) the air is coming from; breath profiles will vary depending on where the exhaled air originates. A fourth limitation of the current literature is that many studies start with known diseased and healthy populations. Because of all these variations in sample selection, sampling technique, and analysis, cross-research validation is challenging. However, the initial results, regardless of algorithm, diagnostic analysis, or sampling technique, show promise that EBC might be able to diagnose severity in COPD patients. Tables 5, 6, and 7 list the strengths and weaknesses of the three most widely used diagnostic techniques.

Table 5

Spirometry Strengths and Weaknesses

\begin{tabular}{ll}
\hline Strengths & Weaknesses \\
\cline { 2 - 2 } Accurate & Underused in clinical setting \\
Reliable & Used inconsistently in clinical setting \\
Noninvasive & Need trained medical personnel to interpret \\
& Results subjective \\
\hline $\begin{array}{l}\text { Note. Adapted from Holz et al. (2008). Assessing airway inflammation in clinical practice- experience with spontaneous sputum } \\
\text { analysis. Biomedical Central Pulmonary Medicine, }\end{array}$ 8, 5. doi: $10.1186 / 1471-2466-8-5$
\end{tabular}


Table 6

Sputum Induction Strengths and Weaknesses

\begin{tabular}{ll}
\hline Strengths & $\frac{\text { Weaknesses }}{\text { Unprocessed sputum contains abundant and }}$ \\
Safety & thick mucus \\
Ease of use & Provides only semiquantitative information \\
Can be done at home & Labor intensive for quantitative cell count \\
Does not require a lot of equipment & Time consuming and not suited for outpatients \\
\hline Note. Adapted from Holz et al. (2008). Assessing airway inflammation in clinical practice - experience with spontaneous sputum
\end{tabular}

analysis. Biomedical Central Pulmonary Medicine, 8, 5. doi: 10.1186/1471-2466-8-5

\section{Table 7}

Exhaled Breath Strengths and Weaknesses

Strengths

Noninvasive

Suited for outpatients

No trained staff required

Easy to use

Repeated sampling - Do not run out of

Note. Adapted from Holz et al.. (2008). Assessing airway inflammation in clinical practice —experience with spontaneous sputum analysis. Biomedical Central Pulmonary Medicine, 8, 5. doi: 10.1186/1471-2466-8-5

\section{$\underline{\text { Weaknesses }}$}

No universal sampling preparation standard Several algorithms

Multiple diagnostic machines

Not sensitive enough

Because each of these techniques has practical limitations, researchers are continuing to test different methods and compounds in EBC in relation to COPD. One compound of particular interest is NO, because NO is linked to airway inflammation in asthma.

Considering that airway inflammation is found in all stages of COPD, NO may be a marker for airway inflammation in COPD.

\section{Nitric Oxide: General Overview}

NO is associated with airway inflammation in asthma and is key to evaluating, managing, and predicting outcomes in asthma patients (Beg et al., 2009). NO may have a positive association with COPD, considering that inflammation of the airway is found in 
all forms of COPD (Beg et al., 2009). Inflammation may be present in the airways, lungs, and pulmonary blood vessels. FENO is a noninvasive, time-saving, highly reproducible, and cost effective method for assessing inflammation (Bazeghi et al., 2011; Beg et al., 2009). This study will investigate eNO as a potential marker for airway inflammation in COPD.

Current research focuses on analyzing NO, eNO, FENO, NO in the alveolar region (CalvNO) and NO in the bronchial region (JawNO). NO is the most basic form and can be separated into alveolar and bronchial. Most past research focuses on eNO or FENO; however, alveolar and bronchial NO studies are increasing.

NO readings are reproducible from one day to the next in healthy individuals and in patients with stable COPD (Rouhos et al., 2011). In addition, comparisons of NO exhaled in one breath and $\mathrm{EBC}$ at varying flow rates found no significant difference due to sampling technique (Lehouck et al., 2010). NO levels increase during periods of exacerbation (Agustí, Villaverde, Togores, \& Bosch, 1999; Bhowmik et al., 2005; Liu et al., 2007). Other factors that affect NO levels in EBC include suffering from the common cold, eating NO-rich foods, working at certain occupations, and smoking tobacco. The amount of NO depends upon the frequency, duration, and the time at which the NO readings were taken in relation to the above factors. In addition, NO measurements may differ significantly depending on the diagnostic device (Borrill et al., 2006; Korn, Telke, Kornmann, \& Buhl, 2010).

Research has shown that NO levels differ between healthy smokers and smokers diagnosed with COPD. However, data was inconclusive when analyzing the effects of 
smoking in the following subgroups of COPD patients: smokers, ex-smokers and healthy COPD patients (Beg et al., 2009; Lehouck et al., 2010). One study demonstrated that FENO levels were elevated in COPD patients compared to controls (56 +/- $28.01 \mathrm{vs.}$ $22.00+/-6.69, p=0.0001$; Beg et al., 2009). However, the sample size was low, with a total of 14 COPD patients included in the sample. Other factors which may have affected the study were that (1) all participants were male; (2) current smokers were included in both the COPD and the control groups; and (3) patients using steroids were included (Beg et al., 2009). However, another study found that eNO is significantly higher in EBC of chronic smokers than in nonsmokers (Liu et al., 2007). COPD-diagnosed individuals contained higher eNO levels in their breath than healthy controls $(9.8+/-0.7$ vs. $5.5+/-$ 0.4, $p<0.0005$; Liu et al., 2007). In addition, when comparing nonsmoking COPD patients with ex-smokers, COPD patients registered higher eNO levels as well $(9.2+/$ 1.2 vs. $5.7+/-0.5, p=0.002$; Liu et al., 2007). Another study that examined NO levels in smokers, ex-smokers, and nonsmoker COPD patients showed no difference in eNO levels (Lehouck et al., 2010). Comparison of healthy ex-smokers and healthy smokers yielded similar results (3.3+/- 0.6 vs. $3.1+/-0.7)$. COPD smokers had slightly higher eNO levels (2.2 +/- 0.6 vs. 2.6 +/- 0.7; Lehouck et al., 2010) than COPD ex-smokers. This study accounted for confounding variables such as gender, current smoking behavior, body mass index (BMI), and age. However, the sample size of COPD patients was small (22 participants). 


\section{Nitric Oxide: Association Between COPD and Nitric Oxide}

One study tested 91 COPD patients with emphysema and chronic bronchitis to determine if there was a relationship between FENO and COPD (Bazeghi et al., 2011). The main focus of this study was to examine flow rates of NO. All patients had a smoking history and BMI was recorded. BMI readings were taken. Patients were allowed to take prescribed medications up to midnight the day before the testing; however, oral corticosteroid therapy was stopped four weeks prior to the exam (Bazeghi et al., 2011). A potential confounder was the inclusion of patients with exacerbations; studies have shown higher eNO readings during exacerbation (Bhowmik et al., 2005). NO levels in patients with severe emphysema were calculated for airway wall concentration (Caw); alveolar concentration of $\mathrm{NO}(\mathrm{Calv})$; and D, the diffusing capacity of NO (DawNO). There were no significant differences among FENO levels and any of these measurements, as proven by the following $p$-values; $p=0.15, p=0.22$, and $p=$ 0.21 respectively (Bazeghi et al., 2011). Results for a study on FENO levels and chronic bronchitis results were not significant, either: Caw $(p=0.31)$, Calv $(p=0.58)$, and $\mathrm{D}(p=$ 0.56; Bazeghi et al., 2011).

A second study with 151 patients—-84 with COPD (55 ex-smokers and 29 smokers) and 67 healthy controls (28 smokers and 39 smokers) — concluded that the tests were unable to differentiate between patients with and without COPD (Lehouck et al., 2010). Comparison of healthy ex-smokers and healthy smokers yielded similar results (3.3 +/- 0.6 vs. $3.1+/-0.7)$. In a comparison of COPD ex-smokers and COPD smokers, COPD smokers had slightly higher results $(2.2+/-0.6$ vs. $2.6+/$ - 0.7 ; Lehouck et al., 
2010). This study accounted for confounding variables such as gender, current smoking behavior, BMI, and age. A potential weakness was that the sample size of COPD patients was small (22 participants). A study of 16 COPD subjects and 8 healthy nonsmokers found that there was no difference between eNO readings in the two groups (Rutgers et al., 1999). NO excretion rates between COPD and healthy patients were observed. NO correlated with sputum eosinophils in patients with COPD $(p=0.009)$ but not with healthy controls (Rutgers et al., 1999). A study comparing both online and offline sampling measurements for eNO found that the sampling methods did not affect eNO levels (Deykin, Massaro, Drazen, \& Israel, 2002). This study tested 28 healthy subjects and 34 asthma patients using different $\mathrm{NO}$ offline or online sampling techniques $(p=$ 0.25 to 0.98 ; Deykin et al., 2002). Despite several studies unable to identify a correlation between NO and COPD, there were two studies that reported positive results. A study using 81 patients (18 nonsmokers, 16 smokers, 47 COPD) found a correlation between NO and COPD (Brindicci et al., 2005). There was a significant negative correlation between $\mathrm{CalvNO}$, and $\mathrm{FEV}_{1}$ against COPD patients and normal healthy smokers $(r=-$ $0.6, p=<0.0001$ ). Measures of the diffusion of NO in airways (DawNO) were elevated in smokers compared to COPD patients. This results in a weak negative correlation between DawNO and $\mathrm{FEV}_{1}$ in all COPD patients and smoking subjects $(r=-0.4, p=0.006)$ (Brindicci et al., 2005). This study had a small sample size of COPD patients $(n=14)$. There was no mention of confounders (such as gender, medication, or age) affecting the sample population. NO readings were taken on a standard chemiluminescence analyzer (Brindicci et al., 2005). 
A study with 13 current smokers with COPD, 8 ex-smokers with COPD, 12 patients with unstable COPD, and 10 smokers with chronic bronchitis found that the correlation between these types of COPD patients was negative for NO levels and lung function as defined by $\mathrm{FEV}_{1}$ (Maziak et al., 1998). The study found that eNO levels in unstable COPD was higher than in COPD ex-smokers, COPD current smokers, and chronic bronchitis groups $(12.7+/-1.5,<0.01)$. Unstable COPD was defined by having exacerbations and/or severe COPD (Maziak et al., 1998). Exhaled NO levels more were elevated in COPD smokers than in individuals who smoked and had chronic bronchitis $(4.3+/-0.5$ vs. $2.5+/-0.5, p<0.05)$ and higher in ex-smoking COPD patients $(p<0.01)$ (Maziak et al., 1998). However, eNO levels demonstrated a negative association with $\mathrm{FEV}_{1}(r=-0.6, p=<0.001$; Maziak et al., 1998). A weakness was that the GOLD standard was not used to categorize COPD patients, as it has been in more recent studies (Maziak 1998).

\section{Nitric Oxide: COPD and Severity}

A study using 81 patients (18 nonsmokers, 16 smokers, 47 COPD) measured forced expiratory NO at several expired flows and found that alveolar FENO is increased and has a positive correlation with COPD and GOLD severity levels (Brindicci et al., 2005). The CalvNO increase was significant in COPD patients, resulting in a positive correlation between $\mathrm{CalvNO}$ and $\mathrm{FEV}_{1}$ in COPD patients and normal healthy smokers (Brindicci et al., 2005). JawNO levels were lower in smokers than in healthy nonsmoking controls. Results for nonsmokers and GOLD Stage I-II and GOLD Stage III-IV were respectively (630.3 +/- 417.7 vs. 716.2 +/- 141.7 vs. $609.4+$ +/- 275.0). However, levels of 
DawNO increased in COPD patients compared with smokers and controls (GOLD Stage I-II at 15.7 +/- 5.1; GOLD Stage III-IV at 25.0 +/- 5.0; nonsmokers (11.0 +/- 2.5); and smokers (11.6 +/- 3.2; Brindicci et al., 2005). A weak negative correlation was found between DawNO and FEV across all COPD and smoking subjects $(r=-0.4, p=0.006$; Brindicci et al., 2005).

Conversely, a cross-sectional study that tested 64 patients (25 with bronchial asthma, 14 with COPD and 25 normal) found that in COPD patients, there was a negative correlation between $\mathrm{FEV}_{1} / \mathrm{FVC}$ ratio and the level of FENO (Beg et al., 2009). COPD patients had higher FENO levels than controls (56.54 +/- 28.01 vs. $22.00+/-6.69, p=$ 0.0001; Beg et al., 2009). A study of 43 patients with COPD found a negative correlation between NO and $\mathrm{FEV}_{1}(r=-0.6, p<0.001$; Maziak et al., 1998). In addition, a casecontrol study with 151 patients, 84 with COPD (55 ex-smokers and 29 smokers) and 67 healthy controls (28 smokers and 39 smokers) found that there was no association between NO (FENO, CalvNO, JawNO) and COPD severity (Lehouck et al., 2010). A multivariate analysis found that gender, age, BMI, GOLD stage, and corticosteroid use had no effect on the study. Rather, CalvNO was the only variable that affected the association ( $p=0.0115$; Lehouck et al., 2010). Therefore, based on current literature, the association between NO and COPD severity is inconclusive.

\section{Occupational Exposure}

One of research aims of this dissertation was to determine if the association between eNO and COPD is affected by occupational exposure. Several studies have reported association between eNO exposure and asthma (Demange, Bohadana, Massin, \& 
Wild, 2009; Lund, Oksne, Hamre, \& Kongerud, 2000; Tossa et al., 2009; Tossa et al., 2010). Some studies have examined the relationship between eNO and occupational exposure without reference to a specific disease outcome (Kim et al., 2003; Ulvestad et al., 2001). To my knowledge, no studies to date have explored whether the role of occupation modifies the association between eNO and COPD. Kim et al. (2003) examined workers exposed to metal-containing fine particles from boilermakers. The study found that eNO concentrations decreased over a 5-day period of when not exposed to the particles, with a -5.5 parts per billion (ppb) mean change $(95 \% \mathrm{CI}:-8.8,-2.1)$. In addition, the mean change in $\mathrm{FEV}_{1}$ and $\mathrm{FVC}$ exhibited the same trend for the same time period, -1.7 L (95\% CI: -0.24, -0.09) and -0.14 L (95\% CI:-0.23, -0.04) for FEV 1 and FVC, respectively (Kim et al., 2003). One reason for the decrease in eNO was that the study environment contained high levels of transition metals such as iron, nickel, and vanadium (Kim et al., 2003), whereas other studies contained a larger amount of ambient air (Demange et al., 2009; Tossa et al., 2009; Tossa et al., 2010)

The studies that demonstrated an increase in eNO with occupational exposure were conducted in a wide range of environments. Most of these studies examined the effects of eNO and occupation on asthmatics. Exhaled NO is a known biomarker for airway inflammation in asthmatics, and different types of occupational exposures have been known to affect eNO readings in asthmatics. Workers are exposed to a variety of factors that can affect airway hyperresponsiveness and lead to increased FENO levels (Demange et al., 2009). A study of 351 bakers and hairdresser apprentices showed an increase in FENO associated with bronchial hyperresponsiveness (OR 2.00, 95\% CI: 1.21 
- 3.32; Tossa et al., 2010). Indoor and outdoor construction workers showed significant differences in FENO (8.4 +/- 1.09 vs. 5.6 +/- 1.07, $p=0.001$; Ulvestad et al., 2001). Indoor lifeguards showed elevated FENO levels compared to outdoor lifeguards (Demange et al., 2009).

Based on these studies, it appears that eNO levels change depending on the type, duration, and concentration of exposure. If occupation modifies of the association between eNO and COPD, then a public health professional using eNO as a biomarker for COPD might misdiagnose a person who works in a high-risk occupation as having COPD when in fact the eNO is related to the job and not the disease. The increase in eNO might be due to an increase in airway inflammation as a result of asthma. Another possibility is that eNO concentration, $\mathrm{FEV}_{1}$, and $\mathrm{FVC}$ readings may actually decrease over time, giving a false-positive reading when diagnosing COPD (Kim et al., 2003). Therefore, occupation must be taken into consideration when analyzing eNO and COPD associations otherwise eNO occupational exposure may confound results.

\section{Confounders}

Potential confounders are age, gender, medications, race, body mass index, tobacco smoking, having other respiratory illnesses, eating and drinking nitrogen-rich foods and beverages, exercising, the presence of other respiratory illnesses, and tobacco smoking. Age: COPD is usually detected in persons aged 40 and over because of the disease's progressive nature. Younger individuals usually have less airway inflammation damage. As the disease progresses with age, so does severity. Therefore, age becomes a potential confounder if age is not matched in the sample population. Gender: In some 
populations, COPD incidence in women $(5.495 \% \mathrm{CI}$ : 5.3-5.6) is higher than in men (2.8 95\% CI: 2.7-2.9; Bang et al., 2009). Exhaled NO in the forms of DawNO and CalvNO showed a significant effect of eNO when compared to COPD $(p=0.049$ and 0.048 respectively; Bazeghi et al., 2011). Therefore, gender must be matched against controls to ensure a representative sample. Race: Different races will have varying degrees of COPD and COPD severity based on socioeconomics, lifestyle, and occupation. Exercise and BMI: Exercising and BMI may confound results as well. Medications: Corticosteroids will reduce the NO levels in the body and help alleviate airway inflammation. One study found that patients taking inhaled steroids had significantly higher eNO levels than those taking little or none (8.2+/- 1.2 vs. $5+/-0.4, p=<0.05$; Maziak et al., 1998). Therefore, all subjects must refrain from taking corticosteroids before testing or the results may be skewed. Nitrogen-rich foods and beverages: Consumption will cause nitrogen levels to increase during testing, so the recommendation is that individuals do not eat or drink several hours before testing. Other respiratory diseases: Having a cold or other respiratory disease such as asthma may affect eNO readings as well. Exacerbations have been linked to higher exhaled nitrogen oxide readings (Agustí et al., 1999). Therefore, patients must document the frequency and type of exacerbation. Smoking: Studies have demonstrated that eNO levels differ between smokers, ex-smokers, patients with COPD who smoke and former COPD smokers (Beg et al., 2009; Brindicci et al., 2005; Liu et al., 2007). Therefore it is important to match cases and controls for the study and document smoking habits prior to testing. 


\section{Summary}

In summary, current research is inconclusive on the association between eNO and COPD (emphysema and chronic bronchitis) and eNO and COPD severity. One of the main limitations of research to date has been the small sample sizes of COPD patients included in the studies. Therefore, this study included a larger sample size from past studies and tested the associations between eNO and COPD (emphysema and chronic bronchitis), Exhaled NO and COPD severity, and occupation and COPD. The methodology to conduct the research is explained in detail in Chapter 3. 
Chapter 3: Research Method

\section{Introduction}

Airway inflammation is found in all forms of COPD. NO and NO derivatives are known markers of airway inflammation present in EBC. Research has shown a correlation between eNO and asthma; however, association between NO derivatives, airway inflammation, and COPD severity is inconclusive. In this study, I analyzed the association between eNO and COPD to determine if eNO could be used as a biomarker for COPD diagnosis.

Current noninvasive techniques such as spirometry often result in under- or misdiagnosis (Jochmann et al., 2010; Lehouck et al., 2010; Smidth et al., 2012; Spyratos et al., 2012). One major limitation of using spirometry in outpatient settings is that training is lacking, and the equipment requires frequent calibration. Moreover, general physicians are not trained to read and interpret results consistently (Holz et al., 2008).

The findings from this study could potentially lead to the development of noninvasive methods and diagnostic tools to diagnose COPD in outpatient settings that will not have the same limitations as spirometry. This may result in early diagnosis, better management, and lower prevalence of late-stage COPD, thereby decreasing complications and mortality rates. Because of ease of use, more primary care physicians are likely to adopt and use it routinely in clinical settings.

In this study, I used NHANES 2007 to 2010 data to test three hypotheses. The first hypothesis posited an association between eNO and COPD, defined as a patient having emphysema and/or chronic bronchitis. The second hypothesis posited an 
association between eNO and COPD severity, as defined by the GOLD standards, which recognize four stages of severity defined by increasing levels of airway inflammation. The third hypothesis posited that a person's occupation can modify the association between COPD and eNO. Environmental factors associated with employment are often under- or not reported in literature examining the association between eNO and COPD (Bazeghi et al., 2011; Brindicci et al., 2005; Lehouck et al., 2010; Liu et al., 2007).

The Center for Disease Control and Prevention's (CDC) National Center for Health Statistics (NCHS) conducts the National Health and Nutrition Examination Survey (NHANES), an annual study that combines interviews and physical examinations

of over 5,000 individuals in the United States (CDC, 2013a). The sample is representative of the United States population, and the data are publicly available on the CDC website (www.cdc.gov/nhanes) for anyone to use and analyze.

\section{Research Design and Approach}

This cross-sectional analysis used NHANES data from 2007-2008 and 2009-2010 to test the association between eNO and COPD. This research design was different from other research studies in several aspects. First, most studies evaluating the relationship between eNO and COPD have been small, clinical studies (Bazeghi et al., 2011;Beg et al., 2009; Liu et al., 2007; Robbins et al., 1996; Rutgers et al., 1999). This study used a large population-based data source; hence, the findings are generalizable to a broader population. Second, most previous research analyzed either the presence of COPD (yes/no) or COPD severity (a matter of degree; Bazeghi et al., 2011; Beg et al., 2009; Bessa et al., 2011; Bhowmik et al., 2005); this study investigated both. Finally, this is the 
first study to my knowledge that has investigated the association between eNO and COPD by occupation.

Data from this study were abstracted from the examination files listed in Tables 8 to 16 . The total sample size for NHANES 2007 to 2010 was $20,686(10,149$ for $2007-$ 2008 and 10,537 for 2009-2010). The sample was restricted to adults 30 years and older, because COPD is a slow-progressing disease that manifests later in life. The typical cutoff is 40 years old, because prevalence increases with age. However, this study included the 30-year cut-off because COPD can be present in younger patients and as shown in the results section, the 30 to 39 -year-old category indeed had a relatively high prevalence (3.6\%) of COPD.

\section{NHANES Data Set}

The NHANES program began in the 1960s and focuses on different populations and health topics. The program became continuous in 1999. NHANES is an ongoing, stratified, multistage probability program of studies that examines 5,000 civilian, noninstitutionalized adults and children in the United States. Fifteen counties/ locations are visited annually where participants are interviewed, physical examinations conducted, and lab tests completed. Interviews are conducted to gather demographic, socioeconomic, dietary, and health-related information (CDC, 2013a). The physical examinations consist of medical, dental, and physiological measurements (CDC, 2013a). The final component is laboratory testing for blood and urine. 


\section{Data Collection}

NHANES data were collected from interviews, physical examinations, and laboratory tests. The NHANES study team consisted of a physician, medical and health technicians, and dietary and health interviewers. Health interviews were conducted in the homes of respondents by a Screener, Sample Person, and Family Interviewer. Data were recorded using the Blaise computer-assisted personal interview (CAPI; CDC, 2013a). Physical examinations were performed in equipped mobile examination centers (MEC) that visited each location in the country. All participants visited the MEC physician for exams that can take up to 3 hours each. The laboratory staff consisted of medical technologists and phlebotomists trained by the American Society for Clinical Pathologists or other organizations in standard laboratory procedures (CDC, 2013a). The medical technologists all held baccalaureate degrees (CDC, 2013a). The phlebotomist had completed training in pediatric techniques. All MEC staff were trained in safety, subject privacy and confidentiality, and cardiopulmonary resuscitation.

NHANES uses a mostly paperless system by incorporating touch-sensitive computer screens, an audio computer-assisted self-interview system, CAPI, computerassisted self-interviews, face-to-face interviews, and on-site electronic questionnaires (CDC, 2013a). The MECs used automated collection procedures. Laboratory components were recorded directly into a computer database. Access to NHANES data is free to the public. 


\section{Constructing Weights}

Sampling data combining two or more 2-year data sets must be weighted to ensure that the sum of the weights matches the survey population (CDC, 2013a). The weights used in the analysis were the examination weight (variable name: WTMEC2YR) and the 4-year (2007 to 2010) weights that were constructed using the following formula (CDC, 2013a).

If addsrvyr in $(5,6)$ then MEC4YR $=1 / 2 *$ WTMEC2YR; $/ *$ for 2007 to 2010 *SDDSRVYR is the survey cycle variable. In this case $5=2007$ to 2008 and $6=$ 2009 to 2010. (CDC, 2013a)

\section{Sample Size Calculation}

The sample size of 1,001 was calculated using the Stata Powerlog power analysis from the UCLA Statistical Consulting Group (UCLA Statistical Consulting Group 2013). COPD is the binary dependent variable. Subjects will have COPD and controls will not. Exhaled nitrogen oxide was a categorical independent variable measured in quartiles and tested against the binary variable COPD. The calculation assumes that $\mathrm{p} 1=0.08$ and $\mathrm{p} 2=$ $0.11(O R=1.42)$ for the proportion of subjects with both exhaled nitric oxide and COPD data. P1 (0.08) was calculated by dividing the number of confirmed physician diagnosed COPD cases $(n=805)$ by the total sample population $(n=10,214)$. P2 $(0.11)$ was calculated by dividing pre-bronchodilator COPD cases $(n=1,160)$ by the total number of subjects $(n=10,214)$. The total sample size of 1,001 was calculated with an alpha of 0.05 and a power of 0.90 . 


\section{Study Variables}

\section{Dependent Variables: Chronic Pulmonary Obstructive Disease (COPD) and COPD}

\section{Severity}

In both the 2007-2008 and the 2009-2010 datasets, COPD (emphysema and chronic bronchitis) was determined by these two questions: "Ever told you had emphysema?" and "ever told you had chronic bronchitis?" (see Table 10; CDC, 2013b, 2013c). The binary variable was formed by individuals with positive responses to one or more of these questions that were coded as $1=$ yes. Individuals who responded negatively to both questions did not have COPD and were coded $0=$ no to form a binary variable.

COPD severity was calculated using individual prebronchodilator spirometry data for the COPD population from NHANES 2007 to 2010, converted from milliliters to liters. A ratio was calculated by dividing $\mathrm{FEV}_{1}$ by FVC. Observed values less than $70 \%$ were divided by predicted values and aligned to the GOLD standard to determine severity as Stage I, II, III, or IV for analysis. All individuals with a predicted value of $\mathrm{FEV}_{1} / \mathrm{FVC}$ greater than or equal to $80 \%$ were placed in Stage I and labeled as mild. Individuals with a ratio between less than or equal to $80 \%$ and greater than or equal to $50 \%$ were defined as Stage II and labeled as moderate. Stage III individuals had ratios less than $50 \%$ were labeled as severe/very severe. Since there were few observations for Stage III and Stage IV, data for these two categories were combined into one category, Stage III.

Observed baseline measurements for $\mathrm{FEV}_{1}$ were provided in NHANES 2007 to 2010 datasets. Predicted values were calculated by dividing the observed $\mathrm{FEV}_{1}$ value by the predicted $\mathrm{FEV}_{1}$ value estimated for an individual of similar age, height, gender, and 
race, using gender- and race-specific reference equations (Hankinson, Odencrantz, \& Fedan, 1999). A correction factor of 0.88 was applied for race/ethnicity category listed as “other.” (Hankinson et al., 1999).

\section{Independent Variable: Exhaled Nitric Oxide}

FENO readings, measured in ppb, were taken during the physical examinations, and the mean of two reproducible readings was recorded in the variable ENXMEAN (CDC, 2013d, 2013e). For the purpose of this analysis, eNO, a continuous variable, was converted into a categorical variable and separated into quartiles.

\section{Effect Modifier: Occupation}

Occupation was as an effect-modifying variable. The type of occupation and length of time spent in that particular occupation may cause eNO levels to increase or decrease. NHANES 2007 to 2010 included a questionnaire about whether individuals were currently working in or had worked in an occupation where there was a risk of NO exposure. Any individuals who responded positively to any of the following questions were considered at risk of exposure to NO and coded $1=$ yes. Individuals who responded negatively to all of these questions were considered not at risk and coded $0=$ no $(\mathrm{CDC}$, 2013f, 2013g). The questions were as follows:

- In any job, have you ever been exposed to dust from rock, sand, concrete, coal, asbestos, silica, or soil?

- In any job, have you ever been exposed to dust from baking flours, grains, wood, cotton, plants, or animals? 
- In any job, have you ever been exposed to exhaust fumes from trucks, buses, heavy machinery, or diesel engines?

- In any job, have you ever been exposed to any other gases, vapors, or fumes?

Table 13 lists the inclusion questions along with more detail from NHANES 2007 to 2010.

\section{Covariate Variables}

Covariates included age, gender, race/ ethnicity, tobacco smoking, and body mass index; whether someone smoked in the home; whether the subject ate or drank within the last hour, ate nitrogen rich foods within the last 3 hours, ate nitrogen-rich vegetables within last 3 hours, smoked within the last hour, exercised strenuously in the last hour, used steroids within the last 2 days, had a cough, cold or other respiratory illness in last 7 days, or had ever been told they had asthma. A complete list of questions is found in Tables 14 and 16 (CDC, 2013b, 2013c, 2013h, 2013i).

\section{Variables - Questions and Coding}

In this section, I describe the NHANES dataset questions and codes in detail. All data came from National Health and Nutrition Examination Surveys 2007-2008 and 2009-2010. 


\section{Demographic Variables:}

Covariate data on age, gender, and race were part of "Demographic Variables and

Sample Weights" data files DEMO_E.xpt and DEMO_F.xpt (CDC, 2013h; 2013i). See

Table 8 .

Table 8

Demographic Data-Description and Coding

\begin{tabular}{llll}
\hline Variable name & Description and coding & Variable type & Study code \\
\hline RIAGENDER & $\begin{array}{l}\text { Gender-male and } \\
\text { female }\end{array}$ & Covariate & Male, Female \\
RIDAGEYR & $\begin{array}{l}\text { Age at screening } \\
\text { adjudicated-recode }\end{array}$ & Covariate & Age \\
RIDEETH1 & $\begin{array}{l}\text { Race/ ethnicity- } \\
\text { recode }\end{array}$ & Covariate & $\begin{array}{l}\text { Mexican American, } \\
\text { Other Hispanic, Non- }\end{array}$ \\
& & & $\begin{array}{l}\text { Hispanic White, } \\
\text { Non-Hispanic Black, } \\
\text { Other race/ Multi- } \\
\text { racial }\end{array}$ \\
\hline
\end{tabular}

The emphysema and chronic bronchitis data were part of "Medical Conditions" documentation, data files MCQ_E.xpt and MCQ_F.xpt (CDC, 2013b; 2013c). See Table 9.

Table 9

COPD Determination: 2007-2010

\begin{tabular}{lll}
\hline Variable name & Description and coding & Study variable \\
\hline MCQ160G & $\begin{array}{l}\text { Ever told that you had } \\
\text { emphysema? }\end{array}$ & COPD \\
MCQ160K & $\begin{array}{l}\text { Ever told you had chronic } \\
\text { bronchitis? }\end{array}$ & COPD \\
\hline
\end{tabular}


The spirometry data were part of the "Spirometry -1 st Test $\& 2^{\text {nd }}$ Test Bronchodilator Studies" documentation data files SPX_E.xpt and SPX_F.xpt (CDC, 2013j; 2013k). See Table 10.

This variable was measured using the GOLD standard that measures $\mathrm{FEV}_{1}$, and FVC and was expressed as a ratio of $\mathrm{FEV}_{1} / \mathrm{FVC}$ (GOLD, 2010). This study used prebronchodilator spirometry testing. Measurements of $\mathrm{FEV}_{1}$ were divided by $\mathrm{FVC}$ for prebronchodilator spirometry testing. A ratio was calculated, and a stage of severity from I to IV was given. Table 11 lists the variables used for the calculation.

Table 10

COPD Severity Determination: 2007-2010

\begin{tabular}{lll}
\hline Variable name & Description and coding & Study code \\
\hline SPXNFVC & Baseline FVC $(\mathrm{mL})$ & FVC-Spirometry \\
SPXNFEV1 & Baseline FEV 1 $(\mathrm{mL})$ & FEV—-Spirometry \\
\hline
\end{tabular}


Table 11

COPD Severity as Defined by GOLD

\begin{tabular}{|c|c|c|}
\hline Severity & $\begin{array}{l}\text { Characterized by airflow } \\
\text { limitation }\end{array}$ & Criteria \\
\hline Mild (I) & $\begin{array}{l}\mathrm{FEV}_{1} / \mathrm{FVC}<0.70, \mathrm{FEV}_{1} \\
>=80 \% \text { predicted }\end{array}$ & $\begin{array}{l}\text { At this stage, the patient } \\
\text { may not be aware that their } \\
\text { lung function is abnormal. }\end{array}$ \\
\hline Moderate (II) & $\begin{array}{l}\mathrm{FEV}_{1} / \mathrm{FVC}<0.70,50 \% \\
<=\mathrm{FEV}_{1}<=80 \% \\
\text { predicted }\end{array}$ & $\begin{array}{l}\text { Symptoms usually progress } \\
\text { at this stage, with shortness } \\
\text { of breath typically developing } \\
\text { on exertion. }\end{array}$ \\
\hline Severe (III) & $\begin{array}{l}\mathrm{FEV}_{1} / \mathrm{FVC}<0.70,30 \% \\
<=\mathrm{FEV}_{1}<=50 \% \\
\text { predicted }\end{array}$ & $\begin{array}{l}\text { Shortness of breath typically } \\
\text { worsens at this stage and } \\
\text { often limits patient's daily } \\
\text { activities. Exacerbations are } \\
\text { seen beginning at } \\
\text { this stage. }\end{array}$ \\
\hline Very Severe (IV) & $\begin{array}{l}\mathrm{FEV}_{1} / \mathrm{FVC}<0.70,<30 \\
\% \text { predicted or } \mathrm{FEV}_{1} \\
<50 \% \text { predicted plus } \\
\text { chronic respiratory } \\
\text { failure }\end{array}$ & $\begin{array}{l}\text { At this stage, quality of life } \\
\text { is very appreciably impaired, } \\
\text { and exacerbations may be } \\
\text { life-threatening. }\end{array}$ \\
\hline
\end{tabular}

Exhaled NO data was part of the "Exhaled Nitric Oxide" documentation data files ENX_E.xpt and ENX_F.xpt (CDC, 2013d; 2013e). See Table12. The variable ENXMEAN contained two reproducible eNO measurements from each participant. The variable was divided into quartiles for this study. See Table 12. 
Table 12

Nitric Oxide Factors: 2007-2010

\begin{tabular}{lll}
\hline Variable name & Description and coding & Study code \\
\hline ENXMEAN & $\begin{array}{l}\text { 2 reproducible FENO } \\
\text { measures }(\mathrm{ppb})\end{array}$ & Exhaled nitric oxide \\
\hline
\end{tabular}

Occupation data was part of the "Occupational-OCG Questionnaire" documentation data files (CDC, 2013f; CDC, 2013g). See Table 13. Occupations with no risk for NO exposure were coded as 0 and those at-risk were coded as 1 . Those who responded affirmative to any of the following questions listed in Table 13 were considered at-risk and coded as 1.

Table 13

Occupation Data

\begin{tabular}{lll}
\hline Variable name & Description and coding & Study code \\
\hline OCQ.510 & $\begin{array}{l}\text { In any job have you ever been exposed } \\
\text { to dust from rock, sand concrete, coal, } \\
\text { asbestos, silica, or soil? }\end{array}$ & $\begin{array}{l}\text { Exposure to rock, } \\
\text { sand, coal, etc. }\end{array}$ \\
OCQ.530 & $\begin{array}{l}\text { In any job have you ever been exposed } \\
\text { to dust from baking flours, grains, } \\
\text { wood, cotton, plants, or animals? }\end{array}$ & $\begin{array}{l}\text { Exposure to baking } \\
\text { dust, grains, cotton, } \\
\text { plants, etc. }\end{array}$ \\
& $\begin{array}{l}\text { In any job have you ever been exposed } \\
\text { to exhaust fumes from trucks, buses, } \\
\text { OCQ.55y machinery, or diesel engines? }\end{array}$ & $\begin{array}{l}\text { Exposure to exhaust } \\
\text { fumes, trucks, buses, } \\
\text { etc. }\end{array}$ \\
& $\begin{array}{l}\text { In any job have you ever been exposed } \\
\text { to any other gases, vapors, or fumes? }\end{array}$ & $\begin{array}{l}\text { Exposure to other } \\
\text { gases/fumes }\end{array}$ \\
\hline
\end{tabular}

Covariate confounders that affect NO and COPD were part of the "Smoking Cigarette Use" documentation data files SMQ_E and SMQ_F, "Exhaled Nitric Oxide" 
documentation data files ENX_E.rpt and ENX_F.rpt, and the "Medical Conditions" documentation data files MCQ_E.rpt and MCQ_F.rpt (CDC, 2013b;2013c; 2013d; 2013e; 20131; 2013m). See Table 14.

Table 14

Covariate Confounding Questions for Nitric Oxide

\begin{tabular}{lll}
\hline Data set code & Question & Study code \\
\hline ENQ040 & Smoked last hour? & Smoked in last hour \\
ENQ050 & $\begin{array}{l}\text { Exercised strenuously } \\
\text { last hour? }\end{array}$ & Exercised \\
Ate or drank last hour? & Ate or drank the last \\
hNQ060 & $\begin{array}{l}\text { Ate NO-rich vegetables, } \\
\text { 3 hours? }\end{array}$ & Ate NO-rich foods \\
ENQ070 & $\begin{array}{l}\text { Ate NO-rich meats, 3 } \\
\text { hours? }\end{array}$ & Ate NO-rich foods \\
ENQ080 & $\begin{array}{l}\text { Used oral or inhaled } \\
\text { steroids, 2 days? }\end{array}$ & Used inhaled steroids \\
ENQ090 & $\begin{array}{l}\text { Cough, cold, resp. } \\
\text { illness, 7 days? }\end{array}$ & Respiratory illness \\
ENQ100 & $\begin{array}{l}\text { Ever been told you had } \\
\text { asthma? }\end{array}$ & Asthma \\
MCQ010 & &
\end{tabular}

Covariate data on smoking behavior was part of the "Smoking-Cigarette Use" documentation data files SMQ_E.xpt and SMQ_F.xpt. (CDC, 20131; 2013m). Smoking status was divided into three categories, "nonsmoker," "current smoker," and "exsmoker." A nonsmoker was defined as any individual who had smoked fewer than 100 cigarettes in their lifetime. Current smokers included all individuals who responded positively to smoking at least 100 cigarettes in a lifetime and smoking cigarettes every 
day. Ex-smokers were defined as those who had smoked at least 100 cigarettes and who replied that they no longer smoked cigarettes. See Table 15.

Table 15

Covariate-Smoking

\begin{tabular}{|c|c|c|c|c|}
\hline Data set code & Question & Response & $\begin{array}{l}\text { Individual } \\
\text { code }\end{array}$ & Study code \\
\hline SMQ020 & $\begin{array}{l}\text { Smoked at least } \\
100 \text { cigarettes in } \\
\text { life? }\end{array}$ & Yes & SMAQUEX2 & Current smokers \\
\hline SMQ020 & $\begin{array}{l}\text { Smoked at least } \\
100 \text { cigarettes in } \\
\text { life? }\end{array}$ & No & SMAQUEX2 & Never smokers \\
\hline SMQ040 & $\begin{array}{l}\text { Do you now } \\
\text { smoke } \\
\text { cigarettes? }\end{array}$ & Every day & SMQ077 & Current smokers \\
\hline SMQ040 & $\begin{array}{l}\text { Do you now } \\
\text { smoke } \\
\text { cigarettes? }\end{array}$ & Some days & SMD641 & Current smokers \\
\hline
\end{tabular}

Body mass index (BMI) data was part of the "Body Measures" documentation data files BMX_E.xpt and BMX_F.xpt (CDC, 2013n; 2013o). See Table 16. Body mass index was divided into three categories, "normal," "medium," and "obese." Normal was defined as any individual with a body mass index of less than 25 . Overweight individuals had a body mass index greater than or equal to 25 but less than 30 . Obese individuals had a body mass index greater than 30 . 
Table 16

Covariate-Body Mass Index (BMI)

\begin{tabular}{lllll}
\hline Data set code & Question & Response & $\begin{array}{l}\text { Individual } \\
\text { code }\end{array}$ & Study code \\
\hline BMXBMI & $\begin{array}{l}\text { Body Mass } \\
\text { Index }\left(\mathrm{kg} / \mathrm{m}^{* * 2}\right)\end{array}$ & Yes & BMXBMI & BMI \\
BMXHT & Height $(\mathrm{cm})$ & Measurement & BMXHT & Height \\
\hline
\end{tabular}

\section{Data Analysis Plan}

Data analysis was performed using STATA/ SE 12, a software program that is able to manage large datasets such as those in the NHANES survey (STATA Corp). Calculations included descriptive statistics, the chi-square test of association for frequency comparison, proportional odds ration regression analysis, and subpopulation regression analysis to test the association between eNO and COPD and the effect of occupation.

Hypothesis 1: There is an association between eNO and self-reported physiciandiagnosed COPD (defined as presence of chronic bronchitis or emphysema) among adult NHANES 2007 to 2010 participants. This hypothesis was tested using NHANES 2007 to 2010 self-reported data by combining the Emphysema and Chronic Bronchitis responses to form the binary COPD variable. All positive responses to "Ever been told you had chronic bronchitis?" or "Ever been told that you had emphysema?" were used to form the binary COPD variable. The variable NO was created by separating the mean average of individual response into quartiles. Descriptive statistics and chi-square analyses were conducted first. Calculations included $p$-values for trend to check for dose-response relationship, odds ratios, and corresponding 95\% confidence intervals. Four models were 
created to test the hypothesis by logistic regression analysis. The first model used an unadjusted univariable logistic regression analysis on all individual variables. The second model was adjusted for sociodemographic variables (age, gender, race, and smoking status) and tested with a multivariable regression analysis. The third model was adjusted for factors that directly affect NO and tested using a multivariable logistic regression analysis. These factors were: if someone smoked in the home; if the individual ate or drank before the study, ate nitrogen rich meats, ate nitrogen-rich vegetables, smoked in the last hour; if they exercised, used steroids, had a respiratory illness, or had asthma. The fourth model was a multivariable regression analysis including all the variables listed above.

Hypothesis 2: Increasing eNO levels are associated with increased COPD severity, as defined by the GOLD standard. This hypothesis was tested using NHANES self-reported data for 2007 to 2010 by aligning $\mathrm{FEV}_{1} / \mathrm{FVC}$ ratios to the GOLD standard stages for severity, associating observed ratios less than $70 \%$ lung capacity with predicted values. Ratios greater than $70 \%$ lung capacity were considered normal and not contained in the GOLD standard. The variable eNO (in quartiles) was based on responses to the "FENO Measurement," using the means of 2 reproducible measurements from each individual. These means were then separated into quartiles. The hypothesis was tested by analyzing the frequency of eNO by quartiles against the frequency of COPD severity as defined by GOLD Stages I, II, III, and IV in pre-bronchodilator spirometry analysis. Data for Stages III and IV data were few and combined into one variable, Stage III. Since the outcome variable, COPD severity, is an ordinal variable, the proportional odds logistic 
regression analysis (also referred to as ordinal logistic regression analysis) was performed. In the proportional odds model, the probability of a larger response is compared to the probability of an equal or smaller response. A univariable ordered logistic regressions analysis was performed first, followed by multivariable ordered logistic regression analyses, adjusted for all confounding variables.

Hypothesis 3: The association between NO and COPD is modified by occupation. This hypothesis was tested using NHANES 2007 to 2010 data by comparing occupation with eNO and COPD results. At-risk occupations were coded as 1 and low-risk occupations as 0 . This variable was created with responses to the Occupation OCQ questionnaire (CDC, 2013f; 2013g). The questions included: "In any job have you ever been exposed to dust from rock, sand, concrete, coal, asbestos, silica, or soil?"; "In any job have you ever been exposed to dust from baking flours, grains, wood, cotton, plants, or animals?"; "In any job have you ever been exposed to exhaust fumes from trucks, buses, heavy machinery, or diesel engines?"; and "In any job have you ever been exposed to any other gases, vapors, or fumes?" To test this hypothesis, data were stratified by atrisk occupation. A univariable analysis and a subpopulation logistic regression analysis were conducted. Odds ratios, along with the corresponding $95 \%$ confidence intervals, were computed for eNO quartiles as described earlier.

\section{Quality}

NHANES quality control and quality assurance is in compliance with the 1988 Clinical Laboratory Improvement requirements (CDC, 2013a). Several methods were used to monitor the quality of the analyses performed by the NHANES contract 
laboratories. First, the equipment and data collection in the MEC are calibrated and checked before the analysis of the survey data is begun (CDC, 2013a). Second, the quality testing performed in the MECs included analyzing "blind" split samples collected during pretesting. Third, random repeat testing was completed on 5\% of the samples. Fourth, the laboratory personnel performance was monitored by NCHS and contract consultants during unscheduled audits using a detailed quality assurance evaluation. Observations of laboratory staff and feedback were provided on equipment use, specimen collection and preparation, survey participant interaction, and survey protocol implementation (CDC, 2013a). In addition, an annual retraining session was conducted. Concerning data processing and preparation, NHANES has guidelines for NCHS and contractors that contain standards for naming variables, filling missing values, and handling missing records (CDC, 2013a). Comments were reviewed and recorded. Prior to testing, all collection materials were screened by the CDC/ NCEH, Environmental Health Laboratory Sciences.

\section{Instrumentation and Materials}

The data collection instrument for this study is secondary data from the NHANES 2007 to 2010 data set. NHANES contains information from interviews, physical examinations, and laboratory results on a representative sample of noninstitutionalized children and adults in the United States. Data sets of four consecutive years must be weighted (CDC, 2013a). Data is available for public use. More information is contained in the Data Weighing section. 


\section{Ethical Considerations and Protection of Human Participants}

NHANES data is free for public use. Participant information in NHANES is protected by the Public Health Service Act (42 USC 242k) and Section 308(d) of that law (42 USC 242m), the Privacy Act of 1974 (5 USC 552A), and the Confidential Information Protection and Statistical Efficiency Act (PL 107-347). There are no ethical concerns related to the recruitment of subjects, materials used, and data collection for this dissertation. All participant data is anonymous and confidential and protected by the CDC. Furthermore, the study was approved by the Walden University institutional review board under reference number 12-12-13-0157824.

\section{Summary}

This quantitative study applied a hypothetico-deductive approach to analyzing the association between NO and COPD using NHANES 2007 to 2010 data. Research areas included analyzing NO and COPD (emphysema and chronic bronchitis), NO and COPD severity, and the effect of occupation on the association between NO levels and COPD. Chapter 4 presents the results of the analyses conducted to test the three hypotheses. 
Chapter 4: Results

The purpose of this quantitative study was to determine the association between eNO and COPD. The research questions and accompanying hypotheses are listed below.

- Research Question 1: Is there an association between eNO and COPD (chronic bronchitis or emphysema) in adults?

- Hypothesis 1: There is an association between eNO and self-reported physician diagnosed COPD (defined as presence of chronic bronchitis or emphysema) among adult NHANES 2007 to 2010 participants.

- Hypothesis 2: Increasing eNO levels are associated with increased COPD severity, defined by the GOLD standard.

- Research Question 2: Does occupation modify the association between eNO and COPD?

Hypothesis 3: The association between NO and COPD is modified by occupation.

I begin Chapter 4 with an overview of the descriptive characteristics and chisquare analysis. The first hypothesis, testing the association between eNO and COPD, was analyzed with four models. The first model was an unadjusted univariable logistic regression analysis of all variables. Model 2 was adjusted for socioeconomic variables. Model 3 was adjusted for factors that affect NO directly. Model 4 was adjusted for all variables. Hypothesis 2 tested the association between eNO and COPD severity through pre-bronchodilator spirometry analysis. The third hypothesis tested whether occupational exposure is an effect modifier of the relationship between eNO and COPD with a 
subpopulation logistic regression analysis. Chapter 4 concludes with a summary and transition into Chapter 5.

\section{Descriptive Characteristics}

NHANES is an annual study that combines interviews and physical examinations of over 5,000 individuals in the United States (CDC, 2013a). The sample is representative of the U.S. population (CDC, 2013a). There were 20,686 participants in NHANES 2007 to 2010; however, the study sample was limited to participants 30 years and older because COPD is rarely observed in younger age groups, resulting in a sample size of 10,214 for the final analysis. Women made up 52\% $(n=5,230)$ of the sample, while $48 \%$ were male $(n=4,984)$. Non-Hispanic whites made up most of the sample at $71 \%(n=4,982)$, followed by non-Hispanic blacks at $11 \%(n=1,951)$. Nonsmokers made up 53\% ( $n=5,287)$ of the study sample; $27 \%$ were ex-smokers $(n=2,815)$, and $20 \%$ were current smokers $(n=2,106)$. Thirty-five percent of responders were overweight $(n=3,446)$ and $37 \%$ were obese $(n=4,274)$.

Exhaled NO data were provided by $81 \%(n=7,474)$ of the sample. These results were grouped into quartiles (see Table 17). Frequency distribution of factors that could directly affect eNO levels ranged from as low as $0.6 \%$ of those reporting that they had exercised strenuously in the last hour to as high as $52 \%$ for those who had eaten or drunk within the last 3 hours before beginning the examination (Table 17).

Nearly $8 \%(n=805)$ of study participants were told by a physician that they had COPD (emphysema or chronic bronchitis). However, after conducting prebronchodilator spirometry analysis, 1,160 were confirmed to have COPD by pre- 
bronchodilator analysis. As a result, $11.4 \%$ of the entire study population were classified as having Stage I $(n=608), 4.8 \%$ had Stage II $(n=478)$, and $0.7 \%$ had Stage III $(n=75)$ COPD (Table 17). Forty-nine percent of study respondents $(n=4,927)$ worked in an atrisk occupation with the potential for exposure to NO.

Table 17

Descriptive Table

\begin{tabular}{|c|c|c|}
\hline Variable & $\begin{array}{c}n \text { (un- } \\
\text { weighted) }\end{array}$ & weighted \\
\hline \multicolumn{3}{|l|}{ Age } \\
\hline 30-39 yrs. & 2045 & 22.5 \\
\hline $40-49$ yrs. & 2057 & 25.0 \\
\hline $50-59$ yrs. & 1876 & 22.7 \\
\hline $60-69$ yrs. & 1960 & 15.1 \\
\hline $70+$ yrs. & 2267 & 14.7 \\
\hline \multicolumn{3}{|l|}{ Gender } \\
\hline Female & 5230 & 52.3 \\
\hline Male & 4984 & 47.7 \\
\hline \multicolumn{3}{|l|}{ Race } \\
\hline Non-Hispanic White & 4892 & 70.8 \\
\hline Other Hispanic & 1081 & 4.6 \\
\hline Mexican American & 1723 & 7.5 \\
\hline Non-Hispanic Black & 1951 & 10.9 \\
\hline Other Race/ Ethnicity & 477 & 6.2 \\
\hline \multicolumn{3}{|l|}{ Smoking } \\
\hline Nonsmoker & 5287 & 53.1 \\
\hline Ex-Smoker & 2815 & 27.0 \\
\hline Current Smoker & 2106 & 19.8 \\
\hline \multicolumn{3}{|l|}{ BMI } \\
\hline Normal & 2494 & 27.9 \\
\hline Overweight & 3446 & 34.8 \\
\hline Obese & 4274 & 37.4 \\
\hline \multicolumn{3}{|l|}{ Factors that can directly affect NO levels } \\
\hline Ate or Drank within the Last Hour & 4525 & 51.9 \\
\hline Ate Nitrogen Rich Meats 3 Hours Before & 257 & 3.0 \\
\hline Ate Nitrogen Rich Vegetables 3 Hours Before & 311 & $\begin{array}{r}4.0 \\
t a\end{array}$ \\
\hline
\end{tabular}




\begin{tabular}{lrr}
\hline Variable & $\begin{array}{r}n(\text { un- } \\
\text { weighted })\end{array}$ & weighted \\
\hline Exercised Strenuously Last Hour & 61 & 0.6 \\
Used Steroids in Last 2 Days & 369 & 4.1 \\
Cough, Cold, or Respiratory Illness Last 7 days & 1620 & 15.5 \\
Ever Been Told you Have Asthma & 1294 & 12.9 \\
Exhaled Nitric Oxide & & \\
1st Quartile (Mean = 6.2) & 2042 & 22.1 \\
2nd Quartile (Mean =11.8) & 1797 & 20.5 \\
3rd Quartile (Mean = 17.6) & 1842 & 20.0 \\
4th Quartile (Mean = 36.5) & 1793 & 18.8 \\
COPD & & \\
No & 9373 & 92.5 \\
Yes & 805 & 7.2 \\
Pre-Bronchodilator & 1160 & 11.4 \\
Stage I & 608 & 6.9 \\
Stage II & 477 & 4.8 \\
Stage III \& IV & 75 & 0.7 \\
At-Risk Occupation & & \\
Not at risk & 4061 & 42.7 \\
At risk & 4927 & 49.4 \\
\hline
\end{tabular}

\section{Chi-Square Analysis}

Chi-square analysis was conducted across all variables against the dependent variable COPD (Table 18). Overall, age was significantly associated with COPD. The prevalence of COPD increased by age. It was as low as $3.6 \%$ in the 30 to 39 -year-old category and as high as $12.5 \%$ in the 60 to 69 -year-old category; it declined slightly to $10.5 \%$ in the $70+$ year old category $(p<0.001)$. More women than men were diagnosed with COPD (4.6 and 2.7 respectively, $p<0.001$ ). Similarly, non-Hispanic whites had the highest prevalence of COPD at $8.2 \%$, followed by non-Hispanic blacks (6.2\%), and other Hispanics $(5.6 \%, p<0.001)$. Smoking was also significantly related to COPD. Exsmokers had the highest prevalence (12.4\%), followed by current smokers $(9.6 \%)$ and 
nonsmokers $(4.1 \%, p<0.001)$. The study respondents who were obese $(\mathrm{BMI}>=30)$ had a higher prevalence of COPD at $8.9 \%(p<0.001)$ than either the normal and overweight individuals.

The prevalence of COPD decreased as eNO concentrations increased by quartiles $(p<0.001)$. All of the potential confounding factors that could affect eNO levels were significantly associated with COPD. Finally, the study respondents who worked in at-risk occupations had higher prevalence of COPD than those who did not work in atrisk occupations ( $8.7 \%$ vs. $5.3 \%, p<0.001$; Table 18$)$.

Table 18

Chi-Square Analyses for the Association Between Various Independent Variables and COPD

\begin{tabular}{lcc}
\hline Variable & COPD & $p$-value \\
\hline Age & & \\
$30-39$ yrs. & 3.6 & $<0.001$ \\
$40-49$ yrs. & 5.8 & \\
$50-59$ yrs. & 6.8 & \\
$60-69$ yrs. & 12.5 & \\
$70+$ yrs. & 10.5 & \\
\hline Gender & & \\
Male & 5.6 & $<0.001$ \\
Female & 8.7 & \\
\hline Race & & \\
Non-Hispanic White & 8.2 & 0.001 \\
Other Hispanic & 5.6 & \\
Mexican American & 2.7 & \\
Non-Hispanic Black & 6.2 & \\
Other Race/ Ethnicity & 5.2 & \\
\hline Smoking & & \\
Nonsmoker & 4.1 & $<0.001$ \\
Ex-smoker & 12.4 & \\
Current Smoker & 9.6 & \\
\hline
\end{tabular}




\begin{tabular}{lcc}
\hline Variable & COPD & $p$-value \\
\hline BMI & & \\
Normal & 6.4 & $<0.001$ \\
Overweight & 6.2 & \\
Obese & 8.9 & \\
\hline Factors that could directly affect eNO & & \\
Ate or Drank within the Last Hour & 6.5 & $<0.001$ \\
Ate Nitrogen Rich Meats 3 Hours Before & 6.4 & $<0.001$ \\
Ate Nitrogen Rich Vegetables 3 Hours Before & 7.6 & $<0.001$ \\
Smoked Within the Last Hour & 12.2 & $<0.001$ \\
Someone Smokes in the Home & 14.2 & $<0.001$ \\
Exercised Strenuously Last Hour & 4.0 & $<0.001$ \\
Used Steroids in Last 2 Days & 30.9 & $<0.001$ \\
Cough, Cold, or Respiratory Illness Last 7 days & 10.2 & $<0.001$ \\
Ever Been Told you Have Asthma & 25.2 & $<0.001$ \\
\hline Exhaled Nitric Oxide & & \\
1st Quartile & 8.7 & $<0.001$ \\
2nd Quartile & 6.1 & \\
3rd Quartile & 5.6 & \\
4th Quartile & 4.8 & \\
\hline At-Risk Occupation & & \\
Not at-risk & 5.3 & $<0.001$ \\
At risk & 8.7 & \\
\hline
\end{tabular}

\section{Research Question 1: Hypothesis 1}

Is there an association between $\mathrm{eNO}$ and $\mathrm{COPD}$ (chronic bronchitis or emphysema) in adults?

Hypothesis 1: There is an association between eNO and self-reported physician diagnosed COPD (defined as presence of chronic bronchitis or emphysema) among adult NHANES 2007 to 2010 participants.

Four models were developed to analyze the hypothesis (Table 19). Model 1 was unadjusted and used odds ratios and corresponding $95 \%$ confidence intervals between eNO quartiles and COPD. Exhaled NO levels were grouped into quartiles: Quartile 1 
ranged from $3.5 \mathrm{ppb}$ to $9.5 \mathrm{ppb}($ mean $=6.3)$, Quartile 2 from $9.5 \mathrm{ppb}$ to $14.5 \mathrm{ppb}$ (mean $=11.8)$, Quartile 3 from 14.5 to $22.5($ mean $=17.6)$, and Quartile 4 ranged from 22.5 to $301($ mean $=36.5)$. The odds of COPD decreased as the amount of eNO increased from as high as 0.68 (95\% CI: $0.51-0.92)$ for Quartile 2 to as low as 0.53 (95\% CI: $0.39-0.73$ ) for Quartile 4 (Table 19). When adjusted for age, gender, race, and smoking status, all odds ratios became statistically nonsignificant (Model 2). The odds ratio of COPD for the second and the third quartiles of eNO exposure remained statistically nonsignificant for Models 3 and 4, and only reached statistical significance for the fourth quartile with a $43 \%$ and $40 \%$ decline in the odds of COPD for Models 3 and 4, respectively.

Table 19

Hypothesis 1 - Model Comparison

\begin{tabular}{|c|c|c|c|c|c|c|c|c|}
\hline \multicolumn{9}{|c|}{ COPD } \\
\hline eNO & $\begin{array}{c}\text { Model } 1 \\
\text { OR }(95 \% \mathrm{CI})\end{array}$ & $p$-value & $\begin{array}{c}\text { Model } 2 \\
\text { OR }(95 \% \mathrm{CI})\end{array}$ & $p$-value & $\begin{array}{c}\text { Model } 3 \\
\text { OR }(95 \% \mathrm{CI})\end{array}$ & $p$-value & $\begin{array}{c}\text { Model } 4 \\
\text { OR }(95 \% \mathrm{CI})\end{array}$ & $\overline{p \text {-value }}$ \\
\hline 1st Quartile & 1.00 & & 1.00 & & 1.00 & & 1.00 & \\
\hline 2nd Quartile & $\begin{array}{c}0.68 \\
(0.51-0.92)\end{array}$ & 0.013 & $\begin{array}{c}0.90 \\
(0.42-0.87)\end{array}$ & 0.554 & $\begin{array}{c}0.94 \\
(0.64-1.38)\end{array}$ & 0.76 & $\begin{array}{c}0.99 \\
(0.66-1.49)\end{array}$ & 0.93 \\
\hline 3rd Quartile & $\begin{array}{c}0.63 \\
(0.44-0.89)\end{array}$ & 0.010 & $\begin{array}{c}0.85 \\
(0.57-1.28)\end{array}$ & 0.431 & $\begin{array}{c}0.91 \\
(0.60-1.36)\end{array}$ & 0.63 & $\begin{array}{c}0.91 \\
(0.58-1.44)\end{array}$ & 0.68 \\
\hline 4th Quartile & $\begin{array}{c}0.53 \\
(0.39-0.73) \\
\end{array}$ & $<0.001$ & $\begin{array}{c}0.79 \\
(0.56-1.28) \\
\end{array}$ & 0.155 & $\begin{array}{c}0.59 \\
(0.40-0.86) \\
\end{array}$ & $<0.05$ & $\begin{array}{c}0.60 \\
(0.42-0.87) \\
\end{array}$ & $<0.05$ \\
\hline
\end{tabular}

Note. Model 1- unadjusted analysis of odds ratio and 95\% confidence interval or OR(CIs)

Model 2 - Model adjusted for age, gender, race, and smoking odds ratio and 95\% confidence interval or OR(CIs)

Model 3 - Model adjusted for factors that can directly affect nitrogen oxide levels (Ate or Drank within Last Hour, Ate Nitrogen Rich Foods within the Last 3 hours, Ate Nitrogen Rich Vegetables within Last 3 Hours, Smoked within the Last Hour, Someone Smokes in the Home, Exercised Strenuously Last Hour, Used Steroids within the Last 2 days, Cough, Cold or Other Respiratory Illness in Last 7 days, Ever Been Told you had Asthma) of odds ratio and 95\% confidence interval or OR(CIs)

Model 4 - Model adjusted for age, gender, race, smoking, BMI, Ate or Drank within Last Hour, Ate Nitrogen Rich Foods within the Last 3 hours, Ate Nitrogen Rich Vegetables within Last 3 Hours, Smoked within the Last Hour, Someone Smokes in the Home, Exercised Strenuously Last Hour, Used Steroids within the Last 2 days, Cough, Cold or Other Respiratory Illness in Last 7 days, Ever Been Told you had Asthma of odds ratio and 95\% confidence interval or OR(CIs)

\section{Research Question 1: Hypothesis 2}

Hypothesis 2: Increasing eNO levels are associated with increased COPD severity, defined by the GOLD standard. 
The GOLD standard has four stages of severity. Data for stage III and IV severity were limited and combined into one category, Stage III. Hence, COPD severity was recategorized into Stage I (mild), Stage II (moderate), and Stage III (severe/very severe; see Table 20). The prevalence of pre-bronchodilator COPD was 11.4\%. Quartile 3 in Model 1 was significant $(p=0.004)$ but the odds ratio was far from the null $(O R=$ $0.52)$, and quartile 4 was slightly better $(O R=0.77)$, demonstrating that confounders had a profound negative association with COPD severity and eNO. All variables in Model 2 were insignificant, and the odds ratios varied significantly. Quartile $2(O R=1.29,95 \%$ CI: $0.80-2.10)$, quartile $3(O R=0.70,95 \%$ CI: $0.41-1.20)$, and quartile $4(O R=1.02,95$ \% CI: 0.68-1.54). Adjusting for confounders shifted the odds ratios in a positive direction, demonstrating that adjusting for covariates shifted all three quartiles closer to the null.

Table 20

Hypothesis 2 - Pre-Bronchodilator Spirometry Results

\begin{tabular}{lllll}
\hline \multicolumn{3}{c}{ Model 1 } & \multicolumn{2}{c}{ Model 2 } \\
\hline NO & OR $(95 \% \mathrm{CI})$ & $p$-value & OR $(95 \% \mathrm{CI})$ & $p$-value \\
\hline $1^{\text {st }}$ Quartile & 1.00 & & 1.00 & \\
$2^{\text {nd }}$ Quartile & $0.94(0.64-1.38)$ & 0.749 & $1.29(0.80-2.10)$ & 0.290 \\
$3^{\text {rd }}$ Quartile & $0.52(0.34-0.80)$ & 0.004 & $0.70(0.41-1.20)$ & 0.185 \\
$4^{\text {th }}$ Quartile & $0.77(0.57-1.04)$ & 0.082 & $1.02(0.68-1.54)$ & 0.907
\end{tabular}

Note. Model 1 - Unadjusted

Model 2 - Adjusted for age, gender, race, smoking, BMI, Ate or Drank within Last Hour, Ate Nitrogen Rich Foods within the Last 3 hours, Ate Nitrogen Rich Vegetables within Last 3 Hours, Smoked within the Last Hour, Someone Smokes in the Home, Exercised Strenuously Last Hour, Used Steroids within the Last 2 days, Cough, Cold or Other Respiratory Illness in Last 7 days, Ever Been Told you had Asthma 


\section{Research Question 2: Hypothesis 3}

Does occupational exposure modify the association between eNO levels and COPD?

Hypothesis 3: The association between NO and COPD is modified by occupation. In the unadjusted analysis (Model 1), among those who worked in at-risk occupations, the odds ratio of COPD decreased from $0.78(95 \% \mathrm{CI}:=0.56-1.12)$ in Quartile 2 to 0.54 (95\% CI: $=0.39-0.76)$ in Quartile 4 (see Table 21$)$. The same trend was not apparent for the not-at-risk group (Table 21). When adjusted for potential confounders, the results did not change substantially (Model 2, Table 21).

Table 21

Hypothesis 3- Association Between Nitric Oxide and COPD Stratified by At-Risk Occupation

\begin{tabular}{|c|c|c|c|c|}
\hline & \multicolumn{4}{|c|}{ At-Risk Occupation } \\
\hline & \multicolumn{2}{|c|}{ Model 1} & \multicolumn{2}{|c|}{ Model 2} \\
\hline & $\underline{\text { Yes }}$ & No & $\underline{\text { Yes }}$ & No \\
\hline NO & OR $(95 \% \mathrm{CI})$ & OR $(95 \% \overline{\mathrm{CI}})$ & OR $(95 \% \mathrm{CI})$ & $O R(95 \% \mathrm{CI})$ \\
\hline 1st Quartile & 1.00 & 1.00 & 1.00 & 1.00 \\
\hline 2nd Quartile & $0.78(0.56-1.12)$ & $0.49(0.25-0.99)$ & $1.17(0.77-1.77)$ & $0.69(0.29-1.64)$ \\
\hline 3rd Quartile & $0.66(0.40-1.08)$ & $0.58(0.32-1.05)$ & $0.94(0.55-1.59)$ & $0.83(0.38-1.81)$ \\
\hline 4th Quartile & $0.54(0.39-0.76)$ & $0.52(0.29-0.94)$ & $0.70(0.51-0.97)$ & $0.52(0.26-1.03)$ \\
\hline
\end{tabular}

Note. Model 1 - unadjusted analysis.

Model 2 - Model adjusted for age, gender, race, smoking, BMI, Ate or Drank within Last Hour, Ate Nitrogen Rich Foods within the Last 3 hours, Ate Nitrogen Rich Vegetables within Last 3 Hours, Smoked within the Last Hour, Someone Smokes in the Home, Exercised Strenuously Last Hour, Used Steroids within the Last 2 Days, Cough, Cold or other Respiratory Illness in Last 7 Days, Ever been told you had Asthma.

\section{Summary}

The first hypothesis tested the association between eNO and COPD. All four models exhibited the same odds ratio trend in that the odds ratios decreased as the concentration of eNO increased. The second hypothesis tested the association between 
eNO and COPD severity based on pre-bronchodilator measurements. Pre-bronchodilator spirometry results showed no statistically significant relationship between eNO and COPD. The third hypothesis evaluated the effect modification by occupation on the association between NO and COPD. At-risk occupational exposure did not appear to modify the association between eNO and COPD in this study. Chapter 5 interprets the findings and compares the results to current literature. 
Chapter 5: Discussion, Conclusions, and Recommendations,

\section{Overview}

This study was performed to investigate the association between eNO and COPD because airway inflammation is present in all forms of COPD and eNO is an established biomarker for airway inflammation in asthmatics. Therefore, there may be a link between eNO and COPD related airway inflammation. This study used NHANES 2007 to 2010 data for analysis. The analysis was restricted to individuals 30 years and over because COPD is a progressive disease and manifests mainly in older individuals. This resulted in a sample size of 10,214. The first hypothesis investigated the association between eNO and self-reported physician-diagnosed COPD. The second hypothesis examined the association between eNO and COPD severity as defined by the GOLD standard. The GOLD standard classifies the degree of respiratory obstruction based on spirometry data into four stages of severity. The greater the obstruction, the more severe the disease.

The first research question had two hypotheses, testing the association between eNO and COPD. The first hypothesis tested the association between eNO and COPD using four different models. Model 1 used a univariable logistic regression analysis. Model 2 used a multiple logistic regression analysis adjusted for potential confounding effects of sociodemographics variables such as race, age, gender, and smoking status. Model 3 analyzed the association between eNO and COPD adjusted for factors that could directly affect eNO levels such as eating nitrogen rich foods, exercising, and taking medications. The fourth multiple logistic regression model adjusted for all variables listed earlier. 
The second hypothesis tested the association between eNO and COPD severity, as determined by pre-bronchodilator measurements, using proportional odds logistic regression analysis (ordinal logistic regression). Because airway inflammation increases as disease progression worsens, there may be a link between eNO levels and COPD severity. COPD severity was calculated as the ratio of $\mathrm{FEV}_{1} / \mathrm{FVC}$ and was categorized based on the GOLD standard into four stages: Stage I (mild), Stage II (moderate), Stage III (severe), and Stage IV (very severe). There were limited Stage III and Stage IV data available. Therefore, Stage III and IV were combined into a single category: severe/very severe.

The second research question analyzed whether occupation modifies the association between eNO and COPD. Working in certain occupations may put individuals at risk of exposure to higher NO levels. Respondents who replied positively to being exposed to harmful gases, dusts, or fumes were considered to be working in atrisk occupations $(n=4,927)$. Another 4,061 responded negatively to the same questions and were considered as working in not-at-risk occupations.

\section{Discussion}

\section{Research Question 1: Is There is an Association Between eNO and COPD in Adults?}

The prevalence of COPD in this study was $7.2 \%(n=805)$ based on physician diagnoses. However, based on pre-bronchodilator spirometry analysis, $11.4 \%(n=1,160)$ of the study population was diagnosed with some form of COPD. The prevalence of COPD severity was $6.9 \%$ for Stage I, $4.8 \%$ for Stage II, and $0.7 \%$ for Stage III. These results are similar to the ones reported by Lindberg et al. (2006), who reported the 
prevalence of mild, moderate, and severe GOLD-COPD as 8.2\%, 5.3\%, and 0.7\%, respectively. The findings from my study further supports the argument made by earlier researchers that COPD is often under- or misdiagnosed in the clinical setting (Bednarek et al., 2008; Jochmann et al., 2010; Lehouck et al., 2010; Lindberg, Bjerg, Rönmark, Larsson, \& Lundbäck, 2006; Smidth et al., 2012; Spyratos et al., 2012). Routine use of spirometry testing in outpatient settings should be encouraged to diagnose, treat, and manage COPD cases early in the disease process to prevent the disease from progressing to a later, more severe stage.

When examining the unadjusted analysis of eNO and COPD, all eNO quartile $p$ values were statistically significant (Quartile $2 p=0.013$, Quartile $3 p=0.010$, and Quartile $4 p<0.001$ ). Odds ratios decreased from 0.68 in Quartile 2 to 0.53 in Quartile 4. However, when adjusted for factors directly affecting eNO (Model 3) and for all variables (Model 4), only Quartile 4 remained statistically significant at $p \leq 0.05$. These results demonstrate that only higher concentrations of eNO are associated with lower odds of COPD. The inverse relationship observed in the current study could possibly be because only $4 \%$ of COPD patients were reportedly using steroids prior to the spirometry testing during the NHANES examination and were likely to be clinically stable; eNO levels rise during acute exacerbations, especially in patients hospitalized with severe COPD (Agustí et al., 1999). Similar findings were also reported by Beg et. al. (2009) who found a negative correlation between $\mathrm{FEV}_{1} / \mathrm{FVC}$ ratio and eNO concentration in COPD patients $(p=0.028)$. In a small clinical study of 32 Dutch subjects (16 with COPD and 16 controls), Rutgers et al. (1999) reported no significant difference in eNO concentrations 
between subjects with and without COPD. Despite the small sample sizes, the results from the current study were consistent with the three studies mentioned before.

Inflammation in COPD is mostly present in small airways and lung parenchyma. This led researchers to partition total eNO into an airway and alveolar fraction. Brindicci et al. (2005) found that COPD severity correlated with an increase in the alveolar fraction of exhaled NO, CalvNO, However, their results were not confirmed by Lehouck et al. (2010) and Bazeghi et al. (2011) who found no correlation between eNO, CalvNO, and COPD severity, consistent with the results of the current study. Hence, the findings of this current study confirm previous data and weaken the prospect of using eNO as a biomarker for COPD.

\section{Research Question 2: Does Occupation Modify the Association between eNO and COPD?}

To my knowledge, this is the first study that has explored effect modification by occupational exposures. This study did not find at-risk occupations to modify the association between eNO and COPD. Although the adjusted odds ratio declined as eNO levels increased, none of the results were statistically significant. This study defined atrisk group as anyone who was ever exposed to a wide range of factors such as dust from rock, sand, asbestos, baking flours, and grains. (see Table 12). This study did not take into account the time between exposure and testing, duration of exposure, and amount of particulates, dust, or fumes the participant was exposed to, all of which could potentially confound the relationship between eNO and COPD. Whether the inverse relationship, albeit statistically nonsignificant, observed in the current study is due to the presence of 
relatively stable COPD patients or an artifact of data should be explored in future studies. Exhaled NO is a known biomarker of airway inflammation in occupational asthma patients (Demange et al., 2009; Lund et al., 2000; Tossa et al., 2009; Tossa et al., 2010) and occupational exposures have been shown to modify the association between eNO and asthma (Tossa et al., 2010). However, the results of the current study conclude that occupation does not modify the relationship between eNO and COPD. More studies are needed to confirm these findings.

\section{Implications for Social Change}

There were two defining questions for COPD in this study; "ever been told you had emphysema?" and "ever been told you had chronic bronchitis?" Eight-hundred five participants replied positively to either question and were labeled as having COPD. COPD is often misdiagnosed or underdiagnosed in the clinical setting, primarily due to underutilization of spirometry in outpatient settings. This study confirms previous data suggesting that spirometry is more sensitive than self-report for detecting early forms of COPD. Effective use of spirometry testing in outpatient settings can lead to early diagnosis and treatment. This will likely reduce progression to later stage COPD, fewer comorbidities and complications related to COPD, a decline in mortality, a decrease in healthcare expenditure, and will result in a healthier population.

\section{Limitations}

NHANES is subject to both sampling and nonsampling errors. Interview data are based on self-reports and subject to error because of recall bias and the participant not understanding the question. Physical examination and laboratory data are subject to 
variations in the measurements. In addition, there is the possibility of examiner or physician error. In order to prevent error, detailed protocols were created and audited by public health professionals and the scientific community. Problems and misinterpretations can be prevented by reviewing the documents, reading the data collection protocols and data collection instruments, and conducting descriptive evaluation of the data at the onset (CDC, 2013a). Prior to data collection, the NHANES staff takes comprehensive training and annual refresher training courses. Selection bias was minimized, as NHANES uses a complex, multistage probability sampling technique for selection. In addition, participants who were interviewed or examined were selected by random subsamples or statistically defined (CDC, 2013a).

Because the Stata statistical software package uses listwise (casewise) deletion in regression analysis (i.e., if a value for one variable is missing, an entire record is excluded from the analysis), it has the potential to drastically reduce the sample size and power of a study. To overcome this limitation, an indicator category for missing values was created for confounding variables with $10 \%$ or more missing values. In this case, the confounding variables were: ate or drank in the last hour, ate NO rich meats, ate NO rich vegetables, performed strenuous exercise in the last hour, and used steroids. Although the current study included a large number of potential confounding variables, residual confounding due to unmeasured variables could not be ruled out.

Data for GOLD Stage III and IV severity were few. To overcome this limitation, Stage III and IV data were combined into a single category (Stage III: severe/ very severe). As a result, the Stage III-IV sample size for this study was larger than that of 
most previous studies. Asthma and COPD can coexist, and sometimes it is difficult to separate them clinically (de Marco et al., 2013; Kim \& Rhee, 2010). There were 366 subjects in the current study who had both asthma and COPD. Removing asthmatics from the analyses did not change the results. Therefore, to maintain the appropriate power, I chose to leave the asthma variable in multiple logistic regression analyses as a potential

confounder. Lastly, due to the cross-sectional nature of the data, reverse causation cannot be ruled out.

\section{Dissemination of Findings}

The goal is to present and publish preliminary and final results at conferences attended by clinicians and researchers interested in COPD. Applications for presentations, poster sessions, and abstracts at several conferences will be completed and submitted. The two proposed conferences are the Breath Analysis Summit and the European Respiratory Society annual conferences to be held in 2015.

\section{Conclusion}

This study finds no association between eNO and COPD and COPD severity. There may be a correlation between high levels of eNO and COPD, but further studies are needed. In addition, GOLD Stage III and IV data were limited, and a larger sample size of later-stage COPD severity is needed to effectively investigate the association. Furthermore, at-risk occupation was not found to be an effect modifier. Future studies that include exposure times and duration are needed to further test this association. An important finding of this study is that COPD is under- or misdiagnosed in the clinical 
setting. Therefore, routine use of spirometry should be encouraged for diagnosis and management of COPD in outpatient settings. 


\section{References}

Agustí, A. G., Villaverde, J. M., Togores, B., \& Bosch, M. (1999). Serial measurements of exhaled nitric oxide during exacerbations of chronic obstructive pulmonary disease. European Respiratory Journal, 14 (3), 523-528.

Albertson, T. E., Louie, S., \& Chan, A. L. (2010). The diagnosis and treatment of elderly patients with acute exacerbation of chronic obstructive pulmonary disease and chronic bronchitis. Journal of American Geriatrics Society, 58(3), 570-579. doi: $10.1111 / \mathrm{j} .1532-5415.2010 .02741 . x$

Avsar, G., \& Kasikci, M. (2010). Living with chronic obstructive pulmonary disease: a qualitative study. Australian Journal of Advanced Nursing, 28(2), 46-52.

Bang, K. M., Syamial, G., \& Mazurek, J. M. (2009). Prevalence of Chronic Obstructive Pulmonary Disease in the U.S. working population: An analysis of data from the 1997-2004 National Health Interview Survey. Journal of Obstructive Pulmonary Disease, 6(5), 380-387. doi:

$10.1080 / 15412550903140899$

Banning, M. (2006). Chronic Obstructive Pulmonary Disease: Clinical signs and infections. British Journal of Nursing, 15(16), 874-880.

Basanta, M., Jarvis, R. M., Xu, Y., Blackburn, G., Tal-Singer, R., Woodcock, A., . . Fowler, S. J. (2010). Non-invasive metabolomic analysis of breath using differential mobility spectrometry in patients with chronic obstructive pulmonary disease and healthy smokers. Analyst, 135(2), 315-320. doi: 10.1039/b916374c 
Bazeghi, N., Gerds, T. A., Budtz-Jørgensen, E., Hove, J., \& Vestbo, J. (2011). Exhaled nitric oxide measure using multiple flows in clinically relevant subgroups of COPD. Respiratory Medicine, 105(9), 1338-1344. doi:

10.1016/j.rmed.2011.03.015

Bednarek, M., Maciejewski, J., Wozniak, M., Kuca, P., \& Zielinski, J. (2008). Chronic obstructive pulmonary disease prevalence, severity and underdiagnosis of COPD in the primary care setting. Thorax, 63(402-407). doi: 10.1136/thx.2007.085456

Beg, M. F., Alzoghaibi, M. A., Abba, A. A., \& Habib, S. S. (2009). Exhaled nitric oxide in stable chronic obstructive pulmonary disease. Annals of Thoracic Medicine, 4(2), 65-70. doi: 10.4103/1817-1737.44649

Bessa, V., Darwiche, K., Teschler, H., Sommerwerck, U., Rabis, T., Baumbach, J. I., \& Freitag, L. (2011). Detection of volatile organic compounds (VOCs) in exhaled breath of patients with chronic obstructive pulmonary disease (COPD) by ion mobility spectrometry. International Journal for Ion Mobility Spectrometry, 14, 7-13. doi: 10.1007/s12127-011-0060-2

Bhowmik, A., Seemungal, T. A., Donaldson, G. C., \& Wedzicha, J. A. (2005). Effects of exacerbations and seasonality on exhaled nitric oxide in COPD. European Respiratory Journal, 26(6), 1009-1015. doi: 10.1183/09031936.05.00047305

Borrill, Z., Clough, D., Truman, N., Morris, J., Langley, S., \& Singh, D. (2006). A comparison of exhaled nitric oxide measurements performed using three different analysers. Respiratory Medicine, 100, 1392-1396. doi:

10.1016/j.rmed.2005.11.018 
Brindicci, C., Ito, K., Resta, O., Pride, N. B., Barnes, P. J., \& Kharitonov, S. A. (2005). Exhaled nitric oxide from lung periphery is increased in COPD. European Respiratory Journal,, 26(1), 52-59. doi: 10.1183/09031936.04.00125304

British Lung Foundation. (2011). Chronic Obstructive Pulmonary Disease (COPD). Retrieved from http://www.lunguk.org/media-and-campaigning/world-copd-day Budweiser, S., Hitzl, A. P., Jörres, R. A., Heinemann, F., Arzt, M., Schroll, S., \& Pfeifer, M. (2007). Impact of noninvasive home ventilation on long-term survival in chronic hypercapnic COPD: A prospective observational study. International Journal of Clinical Practice, 61(9), 1516-1522. doi: 10.1111/j.17421241.2007.01427.x

Budweiser, S., Jorres, R. A., \& Pfeifer, M. (2008). Treatment of respiratory failure in COPD. International Journal of COPD, 3(4), 605-618.

Business Wire. (2011). For the treatment of chronic obstructive pulmonary disease, the highest percentage of surveyed pulmonologists consider Spiriva to be the most efficacious therapy when compared to other currently available agents. Retrieved from http://www.businesswire.com/news/home/20110317005109/en/TreatmentChronic-Obstructive-Pulmonary-Disease-Highest-\%age\#.VBgtXvmSwuc Caress, A., Luker, K., \& Chalmers, K. (2010). Promoting the health of people with chronic obstructive pulmonary disease: Patients' and carers' views. Journal of Clinical Nursing, 19(3-4), 564-573. doi: 10.1111/j.1365-2702.2009.02982.x 
Center for Disease Control and Prevention. (2013a). National Health and Nutrition

Examination Survey; Analytic Guidelines 1999-2010. Vital and Health Statistics.

Retrieved from http://www.cdc.gov/nchs/data/series/sr_02/sr02_161.pdf

Center for Disease Control and Prevention. (2013b). National Health and

Nutrition Examination Survey. 2007-2008 Data Documentation, Codebook, and

Frequencies. Data documentation, Codebook, and Frequencies. Medical

Conditions $\left(M C Q \_E\right)$. Retrieved from

http://www.cdc.gov/nchs/nhanes/nhanes2007-2008/MCQ_E.htm

Center for Disease Control and Prevention. (2013c). National Health and

Nutrition Examination Survey. 2009-2010 Data Documentation, Codebook, and

Frequencies. Data documentation, Codebook, and Frequencies. Medical

Conditions $\left(M C Q \_F\right)$. Retrieved from

http://www.cdc.gov/nchs/nhanes/nhanes2009-2010/MCQ_F.htm

Center for Disease Control and Prevention. (2013d). National Health and

Nutrition Examination Survey. 2007-2008 Data Documentation, Codebook, and

Frequencies. Data documentation, Codebook, and Frequencies. Exhaled Nitric

Oxide (ENX_E). Retrieved from http://www.cdc.gov/nchs/nhanes/nhanes2007-

2008/ENX_E.htm

Center for Disease Control and Prevention. (2013e). National Health and

Nutrition Examination Survey. 2009-2010 Data Documentation, Codebook, and

Frequencies. Exhaled Nitric Oxide $\left(E N X \_F\right)$. Retrieved from

http://www.cdc.gov/nchs/nhanes/nhanes2009-2010/ENX_F.htm 
Center for Disease Control and Prevention. (2013f). National Health and Nutrition Examination Survey. 2007-2008 Data Documentation, Codebook, and Frequencies. Data documentation, Codebook, and Frequencies. Occupation $\left(O C Q \_E\right)$. Retrieved from http://wwwn.cdc.gov/nchs/nhanes/20072008/OCQ_E.htm

Center for Disease Control and Prevention. (2013g). National Health and Nutrition Examination Survey. 2007-2008 Data Documentation, Codebook, and Frequencies. Data documentation, Codebook, and Frequencies. Occupation $\left(O C Q \_F\right)$. Retrieved from http://wwwn.cdc.gov/nchs/nhanes/20092010/OCQ_F.htm

Center for Disease Control and Prevention. (2013h). National Health and Nutrition Examination Survey. 2008-2009 Data Documentation, Codebook, and Frequencies. Data documentation, Codebook, and Frequencies. Demographic Variables and Sample Weights (Demo_E). Retrieved from http://www.cdc.gov/nchs/nhanes/nhanes2007-2008/DEMO_E.htm

Center for Disease Control and Prevention. (2013i). National Health and Nutrition Examination Survey. 2009-2010 Data Documentation, Codebook, and Frequencies. Data documentation, Codebook, and Frequencies. Demographic Variables and Sample Weights (Demo_F). Retrieved from http://www.cdc.gov/nchs/nhanes/nhanes2009-2010/DEMO_F.htm Center for Disease Control and Prevention. (2013j). National Health and Nutrition Examination Survey. 2007-2008 Data Documentation, Codebook, and 
Frequencies. Data documentation, Codebook, and Frequencies. Spirometry $-1^{\text {st }}$ Test \&am ${ }^{p ;}$ 2nd Test Bronchodilator Studies (SPX_E). Retrieved from http://www.cdc.gov/nchs/nhanes/nhanes2007-2008/SPX_E.htm

Center for Disease Control and Prevention. (2013k). National Health and Nutrition Examination Survey. 2009-2010 Data Documentation, Codebook, and Frequencies. Data documentation, Codebook, and Frequencies. Spirometry -1 st Test \& 2nd Test Bronchodilator Studies $\left(S P X \_F\right)$. Retrieved from http://www.cdc.gov/nchs/nhanes/nhanes2009-2010/SPX_F.htm

Center for Disease Control and Prevention. (20131). National Health and Nutrition Examination Survey. 2007-2008 Data Documentation, Codebook, and Frequencies. Data documentation, Codebook, and Frequencies. Smoking Cigarette Use (SMQ_E). Retrieved from http://www.cdc.gov/nchs/nhanes/nhanes2007-2008/SMQ_E.htm Center for Disease Control and Prevention. (2013m). National Health and Nutrition Examination Survey. 2009-2010 Data Documentation, Codebook, and Frequencies. Data documentation, Codebook, and Frequencies. Smoking Cigarette Use $\left(S M Q \_F\right)$. Retrieved from http://www.cdc.gov/nchs/nhanes/nhanes2009-2010/SMQ_F.htm Center for Disease Control and Prevention. (2013n). National Health and Nutrition Examination Survey. 2008-2009 Data Documentation, Codebook, and Frequencies. Data documentation, Codebook, and Frequencies. Body Measures (BMX_E). Retrieved from http://www.cdc.gov/nchs/nhanes/nhanes2007- 
2008/BMX_E.htm

Center for Disease Control and Prevention. (2013o). National Health and Nutrition Examination Survey. 2009-2010 Data Documentation, Codebook, and Frequencies. Data documentation, Codebook, and Frequencies. Body Measures (BMX_F). Retrieved from http://www.cdc.gov/nchs/nhanes/nhanes20092010/BMX_F.htm

Center for Disease Control and Prevention. (2013p). National Health and Nutrition Examination Survey, 2013-2014. Overview. Retrieved from http://www.cdc.gov/nchs/data/nhanes/nhanes_13_14/201314_overview_brochure.pdf

Cosio, B. G., \& Agusti, A. (2010). Update in chronic obstructive pulmonary disease 2009. American Journal of Respiratory and Critical Care Medicine, 181, 655660. doi: 10.1164/rccm.201001-0111UP

de Marco, R., Pesce, G., Marcon, A., Accordini, S., Antonicelli, L., Bugiani, M., .. . Verlato, G. (2013). The coexistence of asthma and chronic obstructive pulmonary disease (COPD): prevalence and risk factors in young, middle-aged and elderly people from the general population. PLoS One, 8(5), e62985. doi: 10.1371/journal.pone.0062985

Demange, V., Bohadana, A., Massin, N., \& Wild, P. (2009). Exhaled nitric oxide and airway hyperresponsiveness in workers: A preliminary study in lifeguards BioMed Central Pulmonary Medicine, 9(53). doi: 10.1186/1471-2466$9-53$ 
Deykin, A., Massaro, A. F., Drazen, J. M., \& Israel, E. (2002). Exhaled nitric oxide as a diagnostic test for asthma: Online versus offline techniques and effect of flow rate American Journal of Respiratory and Critical Care Medicine, 165, 15971601. doi: $10.1164 /$ rccm. 2201081

Djukanovic, R. (2000). Induced sputum--a tool with great potential but not without problems. Journal of Allergy and Clinical Immunology, 105(6 Pt 1), 1071-1073.

Djukanovic, R., \& Gadola, S. D. (2008). Virus infection, asthma, and chronic obstructive pulmonary disease. The New England Journal of Medicine, 359(19), 2062-2064. doi: 10.1056/NEJMcibr0806978

Fens, N., Roldaan, A. C., van der Schee, M. P., Boksem, R. J., Zwinderman, A. H., \& Sterk, P. J. (2011). External validation of exhaled breath profiling using an electronic nose in the discrimination of asthma with fixed airways obstruction and chronic obstructive pulmonary disease. Clinical and Experimental Allergy, 41(10), 1371-1378. doi: 10.1111/j.1365-2222.2011.03800.x

Fens, N., Roldaan, A. C., Zwinderman, A. H., Bel, E. H., \& Sterk, P. J. (2011). Breathomics in pulmonary disease: External validity: Asthma vs COPD. Retrieved from http://dare.uva.nl/document/2/96997

Fens, N., Zwinderman, A. H., van der Schee, M. P., de Nijs, S. B., Dijkers, E., Roldaan, A. C., . . . Sterk, P. J. (2009). Exhaled breath profiling enables discrimination of chronic obstructive pulmonary disease and asthma American Journal of Respiratory and Critical Care Medicine, 180, 1076-1082. doi:

10.1164/rccm.200906-0939OC 
Ferrara, A. (2011). Chronic obstructive pulmonary disease. Radiologic Technology, $82(3), 245-263$.

Garvey, C. (2011). Best practices in chronic obstructive pulmonary disease. Nurse Practitioner, 36(5), 16-22; quiz 22-13. doi:

10.1097/01.NPR.0000396473.61188.11

Glaab, T., Vogelmeier, C., \& Buhl, R. (2010). Outcome measures in chronic obstructive pulmonary disease (COPD): Strengths and limitations. Respiratory Research, 11(79), 1-11. doi: 10.1186/1465-9921-11-79

Global Initiative for Chronic Obstructive Lung Disease. (2010). Spirometry for health care providers: Global Initiative for Chronic Obstructive Lung Disease (GOLD). Retrieved from http://www.goldcopd.org/uploads/users/files/GOLD_Spirometry_2010.pdf

Grant, L. R., Hammitt, L. L., Murdoch, D. R., O'Brien, K. L., \& Scott, J. A. (2012). Procedures for collection of induced sputum specimens from children. Clinical Infectious Diseases, 54 Suppl 2, S140-145. doi: 10.1093/cid/cir1069

Hankinson, J. L., Odencrantz, J. R., \& Fedan, K. B. (1999). Spirometric reference values from a sample of the general U.S. population. American Journal of Respiratory Critical Care Medicine, 159(1), 179-187. doi: 10.1164/ajrccm.159.1.9712108

Health and Safety Executive. (2013). Chronic Obstructive Pulmonary Disease (COPD). Retrieved from http://www.hse.gov.uk/statistics/causdis/copd/copd.pdf Holz, O., Seiler, T., Karmeier, A., Fraedrich, J., Leiner, H., Magnussen, H., . . Welker, L. (2008). Assessing airway inflammation in clinical practice - experience with 
spontaneous sputum analysis. Biomedical Central Pulmonary Medicine, 8, 5. doi: 10.1186/1471-2466-8-5

Holz, O., Zesiger, T., Lavaue-Mokhtari, B., Schuchardt, S., \& Hohfeld, J. M. (2011). Analysis of volatile organic compounds in exhaled breath air with a novel compact spectrometer (smart-nose). American Journal of Respiratory and Critical Care Medicine, 183.

Horváth, I., J., H., Barnes, P. J., Alving, K., Antczak, A., Baraldi, E., . . Wirtz, H. (2005). Exhaled breath condensate: Methodological recommendations and unresolved questions. European Respiratory Journal, 26(3), 523-548. doi: $10.1183 / 09031936.05 .00029705$

Hoth, K. F., Wamboldt, F. S., Bowler, R., Make, B., \& Holm, K. E. (2011). Attributions about cause of illness in chronic obstructive pulmonary disease. Journal of Psychosomatic Research, 70, 465-472. doi: 10.1016/j.jpsychores.2010.10.005

Hutchinson, A., Brand, C., Irving, L., Roberts, P., \& Campbell, D. (2010). Acute care costs of patients admitted for management of chronic obstructive pulmonary disease exacerbations: Contribution of disease severity, infection and chronic heart failure. Internal Medicine Journal, 40, 364-371. doi: 10.1111/j.14455994.2010.02195.x

Imperial College London. (n.d.). Burden of obstructive Lung disease initiative. Retrieved from http://www.boldstudy.org/index.html Jochmann, A., Neubauer, F., Miedinger, D., Torok, S. S., Chhajed, P. N., Tamm, M., \& Leuppi, J. D. (2010). General practitioners' adherence to the COPD 
GOLD guidelines: Baseline data from the Swiss COPD cohort study. Swiss Medical Weekly, 140. doi: 10.4414/smw.2010.13053

Kim, J. Y., Wand, M. P., Hauser, R., Mukherjee, S., Herrick, R. F., \& Christiani, D. C. (2003). Association of expired nitric oxide with occupational particulate exposure. Environmental Health Perspectives. , 111(5), 676-680. doi: 10.1289/ehp.5880

Kim, S. R., \& Rhee, Y. K. (2010). Overlap Between Asthma and COPD: Where the Two Diseases Converge. Allergy, Asthma, \& Immunology Research, 2(4), 209-214. doi: 10.4168/aair.2010.2.4.209

Koczulla, R., Dragonieri, S., Schot, R., Bals, R., Gauw, S. A., Vogelmeier, C., . . . Hiemstra, P. S. (2009). Comparison of exhaled breath condensate pH using two commercially available devices in healthy controls, asthma and COPD patients. Respiratory Research, 10(78), 1-8. doi: 10.1186/1465-9921-10-78

Korn, S., Telke, I., Kornmann, O., \& Buhl, R. (2010). Measurement of exhaled nitric oxide: Comparison of different analysers. Respirology, 15, 1203-1208. doi: 10.1111/j.1440-1843.2010.01847.x

Lee, W., \& Thomas, P. S. (2009). Oxidative stress in COPD and its measurement through exhaled breath condensate. The Clinical and Translational Science Journal,, 2(2), 150-155. doi: 10.1111/j.1752-8062.2009.00093.x

Lehouck, A., Carremans, C., De Bent, K., Decramer, M., \& Janssens, W. (2010). Alveolar and bronchial exhaled nitric oxide in chronic obstructive pulmonary disease. Respiratory Medicine, 104, 1020-1026. doi: 10.1016/j.rmed.2010.01.001 
Lindberg, A., Bjerg, A., Rönmark, E., Larsson, L. G., \& Lundbäck, B. (2006). Prevalence and underdiagnosis of COPD by disease severity and the attributable fraction of smoking Report from the Obstructive Lung Disease in Northern Sweden Studies. Respiratory Medicine, 100(2), 264-272. doi: 10.1016/j.rmed.2005.04.029

Liu, J., Sandrini, A., Thurston, M. C., Yates, D. H., \& Thomas, P. S. (2007). Nitric oxide and exhaled breath nitrite/ nitrates in chronic obstructive pulmonary disease patients. Respirations, 74, 617-623. doi: 10.1159/000106379

Ludan, L. (1982). Science and Hypothesis, Historical Essays on Scientific Methodology. Dialogue, 21(4), 780-782. doi: 10.1017/S0012217300023970

Lund, M. B., Oksne, P., Hamre, R., \& Kongerud, J. (2000). Increased nitric oxide in exhaled air: an early marker of asthma in non-smoking aluminium potroom workers? Occupational and Environmental Medicine, 57, 274-278. doi: 10.1136/oem.57.4.274

Lynes, D. (2010). Diagnosis and management of patients with COPD in primary care. Nursing Standards Journal, 25(8), 49-57; quiz 58. doi: 10.7748/ns2010.10.25.8.49.c8069

M., B., Maciejewski, J., Wozniak, M., Kuca, P., \& Zielinski, J. (2008). Chronic obstructive pulmonary disease: Prevalence, severity and underdiagnosis of COPD in the primary care setting. Thorax, 63(402-407). doi: 10.1136/thx.2007.085456

Malipatil, V., \& McDonald, C. F. (2009). Management of older people with chronic obstructive pulmonary disease. Journal of Pharmacy Practice and Research, 39(4), 302-306. 
Mapel, D.W., Robinson, S.B., Dastani, H.B., Shah, H., Phillips, A.L., \& Lydick, E. (2008). The direct medical costs of undiagnosed chronic obstructive pulmonary disease. Value Health. 11(4). 628-636. doi: 10.1111/j.1524-4733.2007.00305.x

Maziak, W., Loukides, S., Culpitt, S., Sullivan, P., Kharitonov, S. A., \& Barnes, P. J. (1998). Exhaled nitric oxide in chronic obstructive pulmonary disease. American Journal of Respiratory and Critical Care Medicine, 157, 998-1002.

MedlinePlus. (2011). Chronic obstructive pulmonary disease. Retrieved from http://www.nlm.nih.gov/medlineplus/ency/article/000091.htm

Minas, M., Hatzoglou, C., Karetsi, E., Papaionnou, A. I., Tanou, K., Tsaroucha, R., .. . Kostikas, K. (2010). COPD prevalence and the differences between newly and previously diagnosed COPD patients in a spirometry program. Primary Care Respiratory Journal, 19(4), 363-370. doi: 10.4104/pcrj.2010.00034

Nazir, S. A., \& Erbland, M. L. (2009). Chronic obstructive pulmonary disease: an update on diagnosis and management issues in older adults. Drugs \& Aging, 26(10), 813831. doi: 10.2165/11316760-000000000-00000

Oreskes, N. (2003). The role of quantitative models in science, in Models in Ecosystem Science. C. D. Canham, J. J. Cole, \& W. K. Lauenroth (Eds.), The role of quantitative models in science, in Models in Ecosystem Science (pp. 13-31). Princeton, NJ: Princeton University Press.

Popov, T. A. (2011). Human exhaled breath analysis. Annals of Allergy, Asthma \& Immunology, 106(6), 451-456. doi: 10.1016/j.anai.2011.02.016 
Robbins, R. A., Floreani, A. A., Von Essen, S. G., Sisson, J. H., Hill, G. E., Rubinstein, I., \& Townley, R. G. (1996). Measurement of exhaled nitric oxide by three different techniques. American Journal of Respiratory and Critical Care Medicine, 153(5), 1631-1635.

Rocker, G. M., Young, J., \& Simpson, A. C. (2009). Advanced chronic obstructive pulmonary disease: more than a lung disease. Progress in Palliative Care, 17(3), 117-125. doi: 10.1179/096992609X392303

Rouhos, A., Kainu, A., Piirila, P., Sarna, S., Linqvist, A., \& Karjalainen, J. (2011). Repeatability of exhaled nitric oxide measurements in patients with COPD. Clinical Physiology and Functional Imaging, 31, 26-31. doi: 10.1111/j.1475-097X.2010.00975.x

Rutgers, S. R., van der Mark, T. W., Coers, W., Moshage, H., Timens, W., Kauffman, H. F., ... Postma, D. S. (1999). Markers of nitric oxide metabolism in sputum and exhaled air are not increased in chronic obstructive pulmonary disease. Thorax, 54, 576-580.

Smidth, M., Sokolowski, I., Kærsvang, L., \& Vedsted, P. (2012). Developing an algorithm to identify people with Chronic Obstructive Pulmonary Disease (COPD) using administrative data. BioMed Central Informatics and Decision Making, 12(38), 1-7. doi: 10.1186/1472-6947-12-38

Spyratos, D., Chloros, D., \& Sichletidis, L. (2012). Diagnosis of chronic obstructive pulmonary disease in the primary care setting. Hippokratia, 16(1), 1722. 
Stoloff, S. W. (2011). Diagnosis and treatment of patients with chronic obstructive pulmonary disease in the primary care setting: focus on the role of spirometry and bronchodilator reversibility. Journal of Family Practice, 60(4 Suppl Diagnosis), S9-16.

Tonello, A., \& Poli, G. (2011). Rethinking chronic obstructive pulmonary disease. Medical Hypotheses, 76(3), 358-360. doi: 10.1016/j.mehy.2010.10.039

Tossa, P., Bohadana, A., Demange, V., Wild, P., Michaely, J.-P., Hannhart, B., . . Zmirou-Navier, D. (2009). Early markers of airways inflammation and occupational asthma: rationale, study design and follow-up rates among bakery, pastry and hairdressing apprentices. Biomedical Cenral Public Health, 9(113). doi: 10.1186/1471-2458-9-113

Tossa, P., Paris, C., Zmirou-Navier, D., Demange, V., Acouetey, D. S., Michaely, J. P., \& Bohadana, A. (2010). Increase in exhaled nitric oxide is associated with bronchial hyperresponsiveness among apprentices. American Journal of Respiratory Critical Care Medicine, 182(6), 738-744. doi: 10.1164/rccm.200903-0415OC

Trueman, J., \& Trueman, I. (2011). Developing criteria to assist in the palliative phase of COPD. British Journal of Nursing, 20(6), 364-369.

Ulvestad, B., Lund, M. B., Bakke, B., Djupesland, P. G., Kongerud, J., \& Boe, J. (2001). Gas and dust exposure in underground construction is associated with signs of airway inflammation. European Respiratory Journal, 17, 416-421.

Velásquez, A., Durán, C., M., Gualdron, O., Rodriguez, J. C., \& Manjarres, L. (2009). Electronic nose to detect patients with COPD from exhaled breath. Olfaction and 
Electronic Nose. Paper presented at the Proceedings of the $13^{\text {th }}$ International Symposium. American Institute of Physics.

WebMD. (2012). Sputum Culture. Retrieved from http://www.webmd.com/lung/sputumculture?page $=2$

WebMed. (2011). COPD Health Center. Retrieved from http://www.webmd.com/lung/copd/default.htm

World Health Organization. (2011). Chronic respiratory diseases: Chronic Obstructive Pulmonary Disease. Retrieved from http://who.int/respiratory/copd/burden/en/index.html

Zieliñski, J., Bednarek, M., \& Group, K. t. A. o. Y. L. S. (2001). Early detection of COPD in a high-risk population using spirometric screening. Chest, 119(3), 731736. 


\section{Appendix A: Effect of Covariates}

The type of covariate affects the association between eNO and COPD. Regression analyses showed smoking status to be significant; and, as stated above, ex-smokers had a higher odds ratio, so inclusion of only one type of smoker can skew results. Studies adjusting only for age, race and gender, may find no association between eNO and COPD, as in this study sociodemographics was insignificant. Studies that include other covariates such as eating nitrogen rich foods 3 hours before the study, smoking behaviors, having another respiratory illness, and exercising before the study may or may not find an association between eNO and COPD depending on which factors are included in the study and the levels of eNO. In this group, only smoking in the home, exercising before the exam, taking steroids, having a respiratory illness, and having asthma were significant. In addition, low levels of eNO are not associated with COPD, whereas high levels of eNO are associated with COPD in all models except when adjusting for sociodemographic data only. Based on this study, neither a nitrogen-rich diet nor exercise was significant across all models $(p>0.05)$.

Overall, the study found that the prevalence of COPD increases with age, except in the 70+ age category, where the odds ratios actually declined. There was a significant correlation between COPD and steroids across all models $(p<0.05)$. This confirms the work by Liu et al. (2007), which determined there was an association between eNO, COPD, and individuals taking glucocorticoids ( $p$ < 0.00005) (Liu et al., 2007). 
Appendix B: New NHANES Sampling Methodology

A new sampling methodology was introduced in 2007 to 200. In the past, all Hispanics had been oversampled compared to Mexican Americans. The 12 to 15 and 16 to 19 -year age groups were combined to form a single 12 to 19 -year-old group for all races; and for minority groups, the 40 to 59-year groups were split into 40 to 49 and 50 to 59. The last change was that pregnant women were no longer oversampled. 
Appendix C: Reference Equations

Reference equations are derived from Hankison, J. L., Odencrantz, J. R. \& Fedan, K. B. (1999). Spirometric references values are derived from a sample of the general U.S. population. American Journal of Respiratory Critical Care Medicine. 159(1), 179-187. doi: 10.1164/ajrccm.159.1.9712108

$\underline{\text { FVC Reference Equations }}$

Male

- Non-Hispanic White $=-0.1933+0.00064 *$ ager$0.000269 *$ ager*ager+0.00018642*ht*ht

- Non-Hispanic Black (African American) $=-0.1517$ $0.01821 *$ ager+0.00016643*ht*ht

- Mexican American =0.2376-0.00891*ager$0.000182 *$ ager*ager+0.00017823*ht*ht

- Other Race $=$ Non-Hispanic White $* 0.88$

Female

- Non-Hispanic White $=-0.3560+0.01870 *$ ager$0.000382 *$ ager*ager $+0.00014815 * \mathrm{ht} * \mathrm{ht}$

- Non-Hispanic Black $=-0.3039+0.00536^{*}$ ager$0.000265 *$ ager*ager $+0.00013606 * \mathrm{ht} * \mathrm{ht}$

- Mexican American= 0.1210+0.00307*ager$0.000237 *$ ager*ager $+0.00014246 * h t * h t$

- $\quad$ Other Race $=$ Non-Hispanic White ${ }^{*} 0.88$

FEV1 Reference Equation

Male

- Non-Hispanic White $=0.5536-0.01303 *$ ager$0.000172 *$ ager*ager $+0.00014098 * \mathrm{ht} * \mathrm{ht}$

- $\quad$ Non-Hispanic Black $=0.3411-0.02309 *$ ager $+0.00013194 * \mathrm{ht} * \mathrm{ht}$

- Mexican American =0.6306-0.02928*ager+0.00015104*ht*ht

- Other Race $=$ Non-Hispanic White $* 0.88$

Female

- Non-Hispanic White $=0.4333-0.00361 *$ ager$0.000194 *$ ager*ager $+0.00011496 * \mathrm{ht} * \mathrm{ht}$

- Non-Hispanic Black $=0.3433-0.01283 *$ ager$0.000097 *$ ager*ager $+0.00010846^{*} \mathrm{ht} * \mathrm{ht}$

- Mexican American= 0.4529-0.01178*ager-0.000113*ager*ager+0.00012154*ht*ht

- Other Race $=$ Non-Hispanic White *0.88 
Curriculum Vitae - Colin Mitchell

As of December 2014

\section{Education:}

- $\quad \mathrm{PhD}$, Public Health, Concentration in Epidemiology, Walden University, Expected March 2015

- MBA, Marketing Management, Pace University, 2003

○ Member of the International Honor Society for Economics - Omicron Delta Epsilon

- BA Biology, University of Delaware, 1992

\section{$\underline{\text { Scientific Experience : }}$}

Camoleon Knowledge Brokerage, Hamburg, Germany - Chief Business Development Officer September 2009 to Present

Camoleon is an international consulting company that supports the business-to-business process in Pharmaceuticals, Biotechnology, and Medical Devices by offering smart innovative business solutions. My responsibilities include supporting clients with direct business development for unique selling propositions; collaborating with companies with sourcing and change management needs; and using innovation management and due diligence to help clients create products and enter specific markets. 
NAMSA - Biomatech, Lyon, France-Head of European Business Development - January 2005 to September 2009

North American Science Associates is a medical device contract research organization offering testing and consulting services that include but are not limited to: clinical trials, biocompatibility testing, efficacy studies, chemical testing, and consulting services for adherence to global regulatory policies. The most dominant regulatory agencies and markets were: the US Food and Drug Administration (FDA), the Japanese Ministry of Health Labor and Welfare (JMHLW), and various Notified Bodies in Europe. I was responsible for visiting and promoting our technical services to companies across Europe by direct visits or by presenting seminars.

\section{Ciba Specialty Chemicals}

Ciba Specialty Chemicals, Technical Sales Specialist - December 1993 to April 2000

I began my career with Ciba in the quality control laboratory in the pigment division in Newport, DE. From there I moved into a Research and Development position creating and improving pigments synthesis. Afterward, I relocated to the Tarrytown, NY, office and began supporting the Polymer division as a technical specialist. As a technical specialist I was the first point of contact for polymer additive questions for US-based companies. Additional responsibilities involved supporting large companies including Union Carbide, Dow Chemical, and Mobile Chemical. 


\section{Educational Experience:}

Secret Passage - Managing Director - October 2009 to Present, Thonon-les-Bains, France

Secret Passage is a consulting company focused on the educational industry. Main responsibilities were matching educational resources with the international school curriculum, including but not limited to the International Baccalaureate (IB), International Primary curriculum (IPC), United Kingdom National Curriculum (IGSCE), United States Curriculum, and general international or local curriculum in international schools throughout Europe.

Follett Library and International, Chicago, IL. Educational Consultant - September 2000 to June 2004 in the United States and from October 2009 to April 2013 in Europe.

Follett International is a global leader in school materials and educational consulting focusing on supporting the international classroom and library with curriculum specific products and services. I began working for Follett Library in the United States, consulting with over 1,100 schools in western Connecticut and Westchester and Bronx counties in New York. I was responsible for consulting with schools to match our products, such as digital resources and books, with the needs of the schools. After moving to France and working with North American Science Associates, I rejoined the international division of Follett managing Europe and the "stans." This included visiting schools and/ or presenting at conferences around Europe. 


\section{Presentations, Workshops, and Collaborations}

\section{Scientific Presentations, Workshops, and Collaborations}

- “Live Science Management for Hire." Presented at one of the Life Science Days held by Life Science Sweden, a Swedish organization and paper that focuses on the Life Sciences in the Nordics (2010).

- Fraunhofer Institute for Toxicology and Experimental Medicine (ITEM) in Hannover, Germany. Collaborated on a breath research project on behalf of VOCscan (2011).

- $\quad$ Biological Evaluation and Chemical Characterisation - new issues in development and evaluation of medical devices" (2008). I gave a workshop at the Medicoindustrien, a Danish medical device organization based in Copenhagen, Denmark.

\section{Educational Presentations and Workshops}

Presented at the European Council of Independent Schools (ECIS) and Swiss Group of Independent Schools (SGIS)

Understanding the Dynamics of Change in the Next Generation Library Patrons

Collection Development for the 21st Century

MetaData Tags: Cataloging and Processing New Media

eBooks: FollettShelf - eContent Anywhere, Anytime 